\title{
En los confines del Mundo: Canarias en la Antigüedad, del mito a la realidad
}

\section{Trinidad Arcos Pereira}

Universidad de Las Palmas de Gran Canaria

Instituto Universitario de Análisis y Aplicaciones Textuales

(IATEXT)

http://doi.org/10.31939/bierehite/2019.03

\section{Introducción}

Desde la Antigüedad, la imagen de Canarias ha estado unida a los mitos relacionados con el Jardín de las Hespérides, las Islas de los Bienaventurados, los Campos Elíseos..., lo que ha dificultado el entendimiento de los textos que proporcionaban datos sobre su localización, su paisaje o los animales que vivían en ella. Por ello, en este trabajo pretendo mostrar cómo el análisis de estos textos debe ser abordado desde una perspectiva multidisciplinar en la que se aúnen la Filología, la Arqueología, los conocimientos náuticos o la Geografía antigua. Por ello, revisaré los hallazgos arqueológicos de Lanzarote y Fuerteventura y el contexto geográfico en el que se encuentran las Islas, porque nos permitirán arrojar luz sobre la interpretación de los textos. No voy a tratar todos los textos clásicos relacionados con Canarias, sino que he seleccionado aquellos que me parecen más significativos: el Periplo de Hanón, Plutarco, Estrabón, Salustio, Plinio, Pomponio Mela, Solino y Arnobio, y cuatro de autores renacentistas, dos que se refieren a las Islas desde el punto de vista histórico, de Antonio de Nebrija y Lucio Marineo Sículo, y otros dos que mantienen el acercamiento desde el mito, como son el Marc-Antoine Muret y el de Luis Tribaldos de Toledo. 


\section{Canarias en los textos antiguos: la visión mítica}

Los textos que proporcionan una visión mítica de las Islas y que están indisolublemente unidos a Canarias han sido muy bien estudiados por el profesor Marcos Martínez y sus discípulos'. Los antiguos van desplazando los mitos relacionados con los Campos Elíseos, las Islas de los Bienaventurados, el Jardín de las Hespérides, el Jardín de las Delicias, las islas Afortunadas en función de cómo avanzan en el conocimiento del mundo, así, en un primer momento se sitúan en Italia, luego en Iberia, para terminar en el confín del Océano, donde ya no hay que volver a desplazarlos. Es necesario estudiar esta visión mítica, porque nos va dar la visión que el imaginario occidental tiene muchas veces vinculado a las Islas. No es, por tanto, un estudio superfluo, pues nos permite conocer la imagen que tienen los otros de nosotros. Ese tipo de mitos van a configurar una descripción de las Afortunadas, que está muy vinculada a un locus amoenus, un lugar agradable, relacionado con el paisaje de la poesía bucólica, un lugar fuera del espacio y del tiempo en el que era posible vivir sin fatigas, como en la época de Saturno, en la Edad de Oro, en la que no había que trabajar y en la que solo era necesario ocuparse de tener conversaciones filosóficas, participar en coros, disfrutar de la música o practicar ejercicio físico. Un lugar que disfruta de la eterna primavera, los suaves vientos,

\footnotetext{
1 Marcos Martínez (1992), “Canarias en la Mitología: historia mítica del archipiélago, Santa Cruz de Tenerife; (1996), Las Islas Canarias de la Antigüedad al Renacimiento: nuevos aspectos, Santa Cruz de Tenerife; (1999), "Las Islas de los Bienaventurados: historia de un mito en la literatura griega arcaica y clásica", Cuadernos de Filología Clásica: estudios griegos e indoeuropeos 9, 243-279; (2010), "Islas míticas en relación con Canarias", Cuadernos de Filología Clásica: estudios griegos e indoeuropeos 20, 139-158; (2014), "Las Islas de los Bienaventurados / Afortunadas en las literaturas griega y latina de las épocas helenística e imperial (I)", en Ángel Martínez Fernández (coord.), Agalma: ofrenda desde la Filología Clásica a Manuel García Tejeiro, Valladolid, 941-948; (2014), "Las Islas de los Bienaventurados / Afortunadas en las literaturas griega y latina de las épocas helenística e imperial (II)", en Luis Miguel Pino Campos - Germán Santana Henríquez (eds.), Kalos kai agazos aner. Didascalou paradeigma: homenaje al profesor Juan Antonio López Férez, Madrid, 549-448; José Manuel Montesdeoca Medina (2007), "Las Islas Canarias en los islarios (I)”, Fortunatae 18, 107-124; (2008), "Las Islas Canarias en los islarios (I)", Fortunatae 18, 101-126.
} 
que tiene bosques, riqueza de animales, abundantes cosechas, es decir todos los elementos que luego se van a ir vinculando de una manera u otra a las Islas.

Pero acercarnos a los textos solo desde el punto de vista mítico plantea otros problemas. En primer lugar, nos va a sesgar la interpretación de los textos. Si sólo vemos el mito, no creeremos los datos o los tergiversará. Por otro lado, como esa ha sido la visión que se ha tenido de las Islas es más sencillo inclinarse hacia esta interpretación. Sin embargo, los textos proporcionan datos que son fidedignos, como afirman muchos investigadores. Si creemos a Plinio, cuando describe la parte del Norte de África, y lo consideramos una fuente fiable ¿por qué se pone en duda el texto de Juba? Si creemos cierta la descripción de las plantas y de los animales incluidos en la Naturalis Historia ipor qué cuestionamos la parte referida a Canarias? Es una incongruencia que hay que abordar estudiando los textos desde una nueva perspectiva. Por ejemplo, veamos el texto de Plutarco de la vida de Sertorio²:

Alí le informaron unos marineros que habían venido hacía poco de las islas del Atlántico. Estas son dos, separadas por un estrecho muy pequeño, distan 10.000 estadios de Libia y son llamadas de los Bienaventurados. En raras ocasiones distrutan de lluvias abundantes; la mayoría de las ocasiones disfrutan de vientos suaves y portadores de rocío; no sólo tienen una tierra fértil y buena para arar y sembrar, sino también producen frutos que crecen por sí mismos, que son suficientes por su abundancia y dulzura para alimentar sin dificultad y sin esfuerzo a un pueblo ocioso. La bonanza en las estaciones y la suavidad de su cambio son el rasgo característico de las islas. El bóreas y el apeliota, que soplan de tierra adentro y que llegan a través de la distancia a un lugar abierto, amainan y pierden fuerza; y los vientos marinos, el ábrego y el céfiro que traen del mar

2 Las traducciones, salvo que se diga lo contrario, son mías. 
lluvias intermitentes y suaves, la mayoría de las veces refrescándolas con suaves brisas dulcemente las alimentan, de tal manera que se ha extendido hasta aquellos bárbaros la firme creencia de que allí están los Campos Elíseos y la mansión de los Bienaventurados que cantó Homero. (Plutarco, Sert. 8)

En este texto, la mayoría se detiene siempre en la parte que no está subrayada, que es la descripción de un locus amoenus, y pasamos por alto los datos: que son dos, que están separadas por un estrecho muy pequeño y que distan 10.000 estadios de Libia; y, al final del texto, el hecho de que los que viven allí piensan que son el lugar donde estaban los Campos Elíseos y la mansión de los Bienaventurados. Es decir, datos que son reales quedan oscurecidos, porque solo se atiende a la descripción del locus amoenus. Por tanto, como ya Marcos Martínez había apuntado en el primero de sus libros ${ }^{3}$ : hay que deslindar la parte mítica de los datos reales, porque no se pueden abordar los textos desde un único punto de vista.

Un segundo problema es el hecho de que los textos que se refieren a las Islas están relacionados con las rutas comerciales y nadie revela las vías por las que llega a los lugares donde consiguen sus productos: púrpura, sal o madera. Nadie espera hoy día encontrar en Internet cuáles son los medios que utiliza la NASA para llegar a Marte y, por tanto, tampoco los vamos a encontrar en los textos antiguos. Si a ello añadimos que muchos de los textos sobre rutas marítimas formaban parte de las cuestiones de estado para Roma y no estaban al alcance de todos, evidentemente vamos a tener una información incompleta. Por otro lado, no contamos con textos que estaban relacionados con Canarias. Entre ellos, la pérdida más importante es la desaparición del libro de Juba sobre África, que nos

3 Marcos Martínez (1992), Canarias en la Mitología: historia mítica del archipiélago, Santa Cruz de Tenerife. 
hubiera proporcionado mucha información, pero, lamentablemente, la obra de Juba solo la conocemos de manera indirecta.

Por último, es evidente que los textos que nos han llegado mezclan datos reales con leyendas, lo que es lógico, pues se intenta enmascarar los destinos en los que hay intereses comerciales, llenándolos de monstruos, de dificultades para llegar, para disuadir a los posibles competidores. Si estos lugares se encuentran, además, en el confín del mundo, es más fácil que estos elementos de disuasión sean más creíbles y más efectivos.

\section{La situación geográfica y las evidencias arqueológicas}

En este nuevo acercamiento a los textos se deben tener en cuenta en primer lugar la situación geográfica y las evidencias arqueológicas de las excavaciones realizadas en las Islas, porque nos proporcionarán datos relevantes para un mejor entendimiento de los textos.

\section{La situación geográfica y el contexto regional}

La situación geográfica de las Islas es suficientemente conocida y no voy a insistir en ella. Si observamos las corrientes regionales, estas permiten un rápido acceso desde Gades, que no olvidemos es una potencia económica de la zona en esta época, pues es más fácil llegar al archipiélago a través del Atlántico que con una navegación de cabotaje ya que las corrientes arrastran a los barcos hasta él, que actuaría como un salvavidas para todas las naves que puede venir desde el norte.

A ello hay que añadir la disposición de las islas frente a África, que establece una diferencia fundamental entre Lanzarote-Fuerteven- 
tura frente al resto del archipiélago. Las primeras están colocadas frente a la costa africana en posición perpendicular frente a la posición horizontal que tienen las demás islas. Además, Lanzarote y Fuerteventura están situadas sobre la plataforma continental africana, mientras que el resto de las islas están en el mar abierto (Fig. 1)

Estas características cambian de manera radical cualquier aproximación que tengamos que hacer a los textos, pues la disposición geográfica marca el radio de accesibilidad a las islas y su visibilidad ${ }^{5}$, y es evidente que el Teide es un faro que se puede ver a muchísima distancia y que supone una atracción para todo el que navegue por la zona.

En la siguiente ilustración se pueden ver las distintas distancias en el siguiente mapa, en el que aprecia la cercanía de las islas orientales a África desde Cabo Jubi, especialmente de Lanzarote y Fuerteventura, y la mayor distancia de las islas occidentales, desde Cabo Bojador (Fig. 2).

En la siguiente ilustración, los radios de accesibilidad nos muestran claramente que a Lanzarote y a Fuerteventura se puede llegar en menos de una jornada de navegación desde Cabo Jubi, mientras que el trayecto a La Palma, la más alejada, se alarga hasta cuatro. (Fig. 3).

\footnotetext{
4 Las ilustraciones son de Antonio Santana Santana y mías, salvo que se indique lo contrario.

5 Antonio Santana Santana - Trinidad Arcos Pereira - Pablo Atoche Peña - José Martín Culebras (2002), El conocimiento geográfico de la costa noroccidental de África en Plinio: la posición de las Canarias, Hildesheim - New York, 201-203.
} 


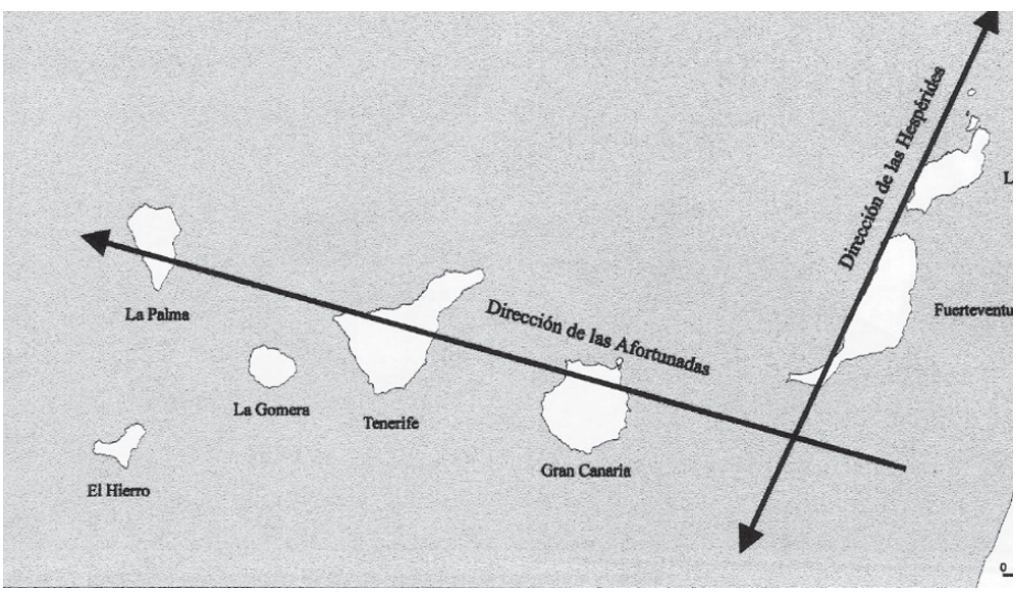

Fig. 1: Disposición de las Islas Canarias respecto a África

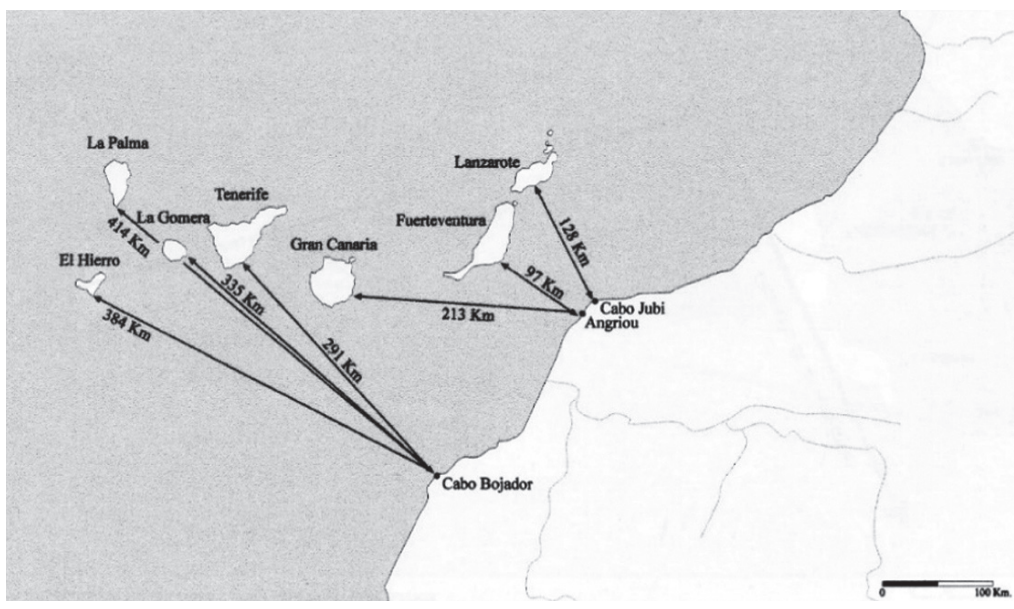

Fig. 2: Distancias desde África

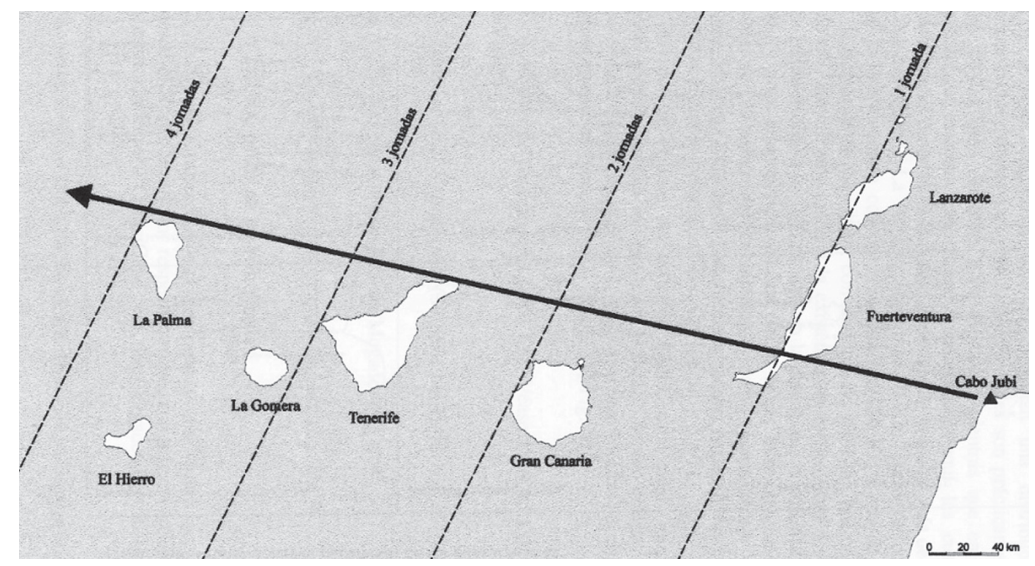

Fig. 3: Radios de accesibilidad al archipiélago Canario desde Cabo Jubi 
Asimismo, no podemos olvidar la abundancia de recursos naturales que tenían las Islas: la riqueza del banco canario-sahariano, pues las rutas de los túnidos pasan muy cerca del archipiélago, lo que facilita la existencia de asentamientos para explotar sus capturas; las salinas; asimismo, en esta época debía de haber también una gran riqueza maderera, con bosques de árboles de alto porte, como nos dice Plinio en su descripción de Invallis. Hay que añadir la púrpura, que se pagaba a precio de oro ${ }^{6}$. Hasta ahora habíamos imaginado que se podría haber extraído purpura en las Islas, pero que, desde la excavación de Lobos, no puede negarse que es uno de los recursos importantes del archipiélago en esta época. Por tanto, es una zona que, estando en el confín del mundo, es, sin embargo, apetecible desde el punto de vista comercial.

Hay que mencionar, también, los diferentes grabados rupestres en los que se representan barcos que, a pesar de los problemas que plantea su datación y en los que no voy a entrar, nos muestran diferentes tipos de navíos, que permiten reconocer algunos que son propios de la navegación antigua ${ }^{7}$ (Fig. 4).

\section{Las excavaciones arqueológicas}

Entre las excavaciones realizadas en las Islas hay que mencionar, especialmente, las que han realizado Pablo Atoche y María Ángeles Ramírez en El Bebedero, en El Rubicón y en Buenavista (Lanzarote), que nos van a dar una serie estratigráfica muy amplia en El Bebedero y Buenavista, que llega hasta época romana, y en El Rubicón, que solo proporciona datos para la época fenopúnica (Fig. 5).

6 Alfredo Mederos Martín - Gabriel Escribano Cobo (2006), “Producción y comercio de la púrpura en el litoral Atlántico norteafricano", Rivista di Studi Fenici 34, 1, 71-95.

7 Antonio Santana Santana - Trinidad Arcos Pereira, (2006) "Las dos islas Hespérides atlánticas (Lanzarote y Fuerteventura, Islas Canarias, España) durante la Antigüedad: del mito a la realidad", Gerión 24, 85-100 (en 88-90). 


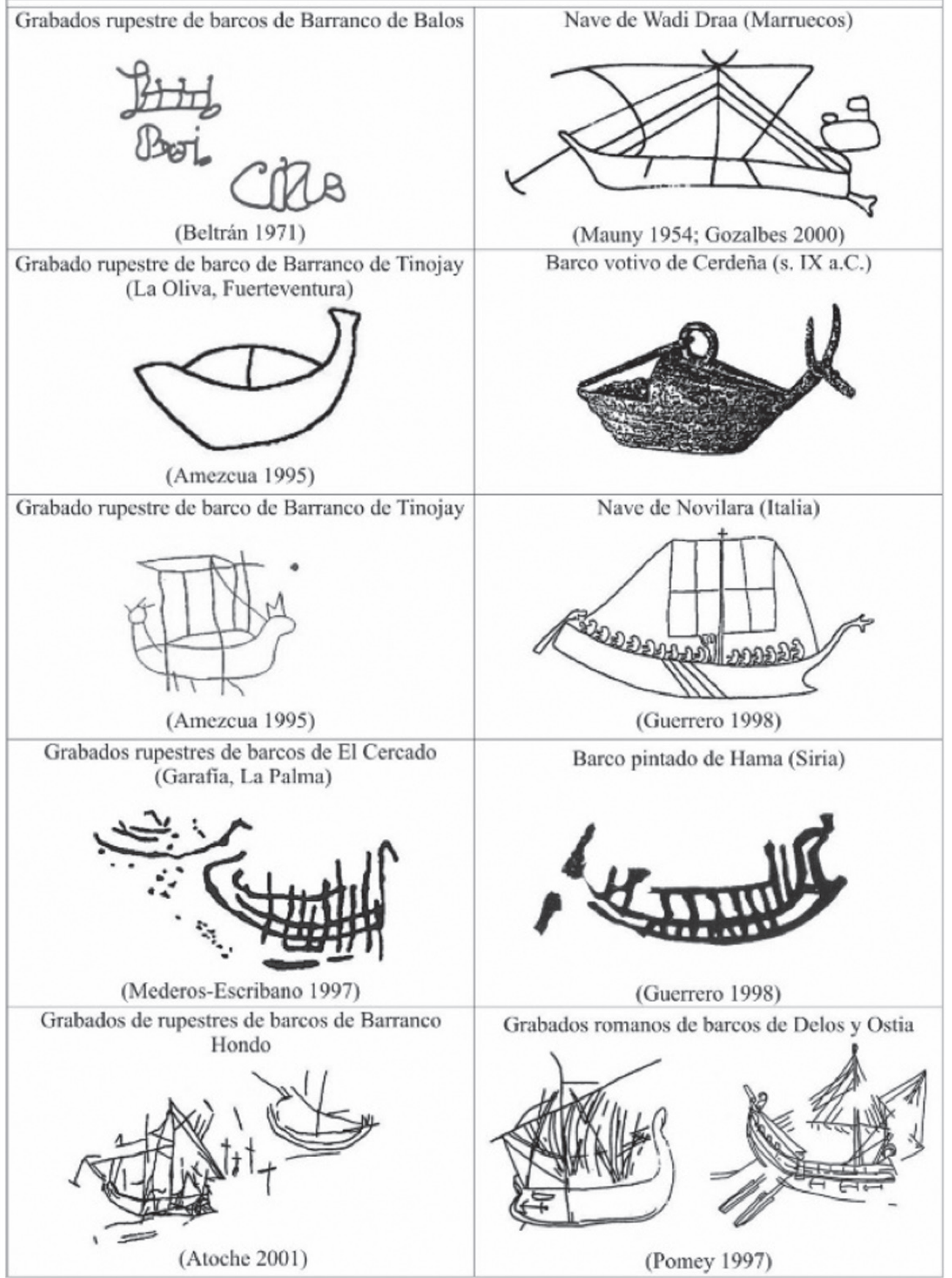

Ilustración 4: Grabados rupestres de barcos de Canarias y paralelismos 
El Bebedero está en un entorno de costa, como es habitual, y en él, en una serie estratigráfica amplia, se han encontrado dataciones entre los siglos I a.C. y IV d.C., el estrato que nos interesa, en el que han aparecido cerámica a torno, materiales metálicos y un abalorio vítreo. Un problema que siempre se ha aducido contra la presencia romana en las islas es el hecho de que no haya edificios, lo que se explica porque el tipo de asentamiento en las islas es muy distinto del de otros lugares, como Baelo Claudia u otro similar, es decir, no hay un asentamiento permanente con una fundación de ciudad al estilo romano. Lo que encontramos son elementos para facilitar el trabajo que permita la explotación de los recursos. No hay, por tanto, un circo, un teatro o una ciudad con la planta romana. Por ello, también hay que acercarse a estos yacimientos arqueológicos y a los artefactos que se encuentran en ellos con una mentalidad más abierta de lo que habitualmente se hace. Tenemos materiales cerámicos y en lo que se refiere a los hallazgos de ánforas en La Graciosa, hemos tenido problemas, pues se presentaron como romanas y, sin embargo, algunas de ellas se consideraron más tarde bajomedievales; este hecho ha arrojado dudas sobre los descubrimientos de cerámicas romanas en las islas, porque hay ánforas romanas y otras que no lo son ${ }^{8}$. Las que se han encontrado en $\mathrm{El}$ Bebedero son romanas, porque lo que se ha analizado han sido las pastas y estas han confirmado su procedencia mayoritaria de la Bética, como es lógico, pues estamos en la zona de influencia del Círculo del Estrecho, aunque no faltan algunas vinculadas a la zona de Campania y Cartago'(Fig. 6).

8 Alfredo Mederos Martín - Gabriel Escribano Cobo (1997), "Una etapa en la ruta Mogador-Canarias: cerámica romana en Lanzarote y su relación con hallazgos submarinos", SPAL. Revista de Prehistoria y Arqueología 6, 221-242.

9 Pablo Atoche et al. (1989), El yacimiento arqueológico de "El Bebedero" (Teguise, Lanzarote). Resultados de la primera campaña de excavaciones, La Laguna; Pablo Atoche (1993), “Excavaciones arqueológicas en 'El Bebedero' (Teguise, Lanzarote). Segunda campaña 1987", Eres: Arqueología / Bioantropología 4, 7-19; Pablo Atoche (1995-1996), "Resultados preliminares de la tercera campaña de excavaciones arqueológicas en 'El Bebedero' (Teguise, Lanzarote) 1990", Vegueta: Anuario de la Facultad de Geografía e Historia 2, 30-44; Pablo Atoche et al. (1995), Evidencias arqueológicas del mundo romano en Lanzarote (Islas Canarias). Arrecife; Pablo Atoche Peña - Ma Ángeles Ramírez Rodrí- 


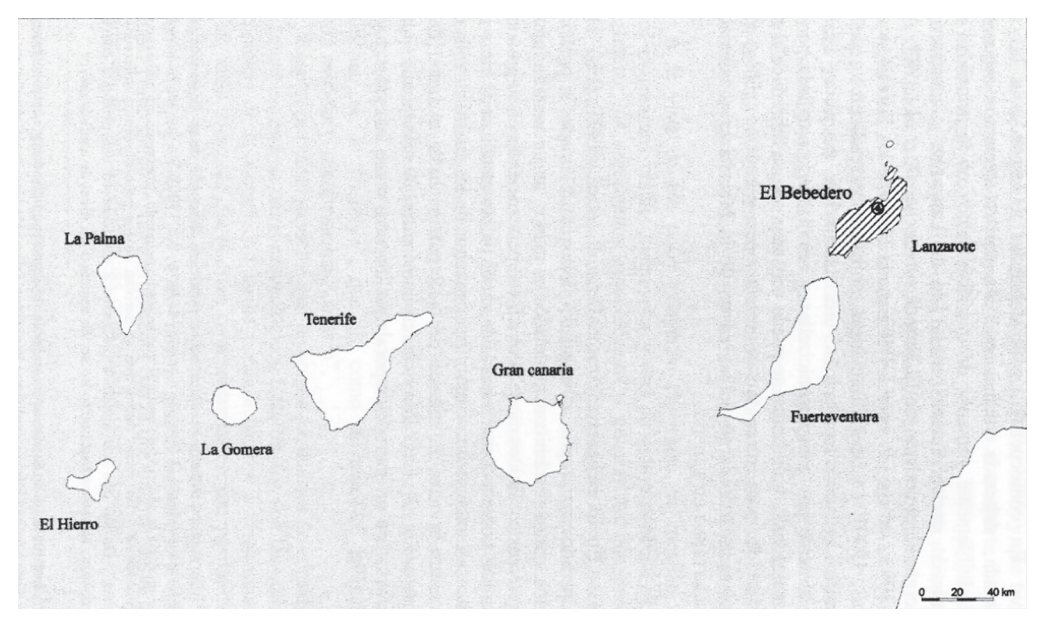

Fig. 5: Localización del yacimiento de El Bebedero

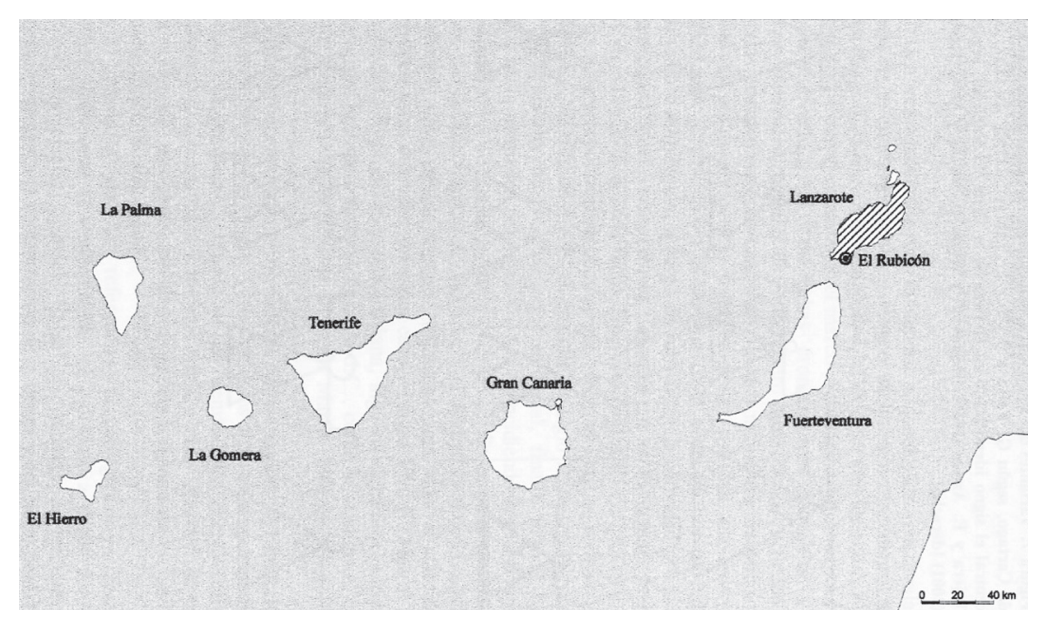

Fig. 6: Localización del yacimiento de El Rubicón

guez (2017), "C14 references and cultural sequence in the Proto-history of Lanzarote (Canary Islands)", Iber-Crono. Actas del Congreso de Cronometrías Para la Historia de la Península Ibérica, Barcelona, 272-285. 
Otra excavación se localiza en El Rubicón, en la Playa de los Pozos (Yaiza). En esta playa hay dos pozos, el Pozo de la Cruz, el más antiguo, en el que se encuentra un signo de Tanit en uno de los dinteles y que Pablo Atoche y María Ángeles Ramírez relacionan con contactos con las culturas fenopúnicas, y podomorfos, de época más tardía. El otro es el Pozo de San Marcial, de factura romana, datado entre los siglos I a.C. y III/IV d.C., que es el periodo de vinculación de las Islas con el Imperio: expedición de Juba II, que recoge Plinio, por un lado, y, por otro, finales del III y principios del IV, cuando se produce la crisis económica y el abandono de las zonas más extremas del Imperio, como las islas británicas o Canarias. Se constata que no hay una permanencia continuada, sino que hay periodos de utilización, de abandono y de reutilización, lo que es normal cuando las secuencias estratigráficas son tan grandes ${ }^{10}$ (Fig. 7).

En Buenavista, tenemos una estructura de planta cuadrangular, de roca volcánica local (basalto) y una secuencia estratigráfica muy amplia que va del siglo X a.C. al III d.C., con periodos de utilización y abandono, que coincide con las que hemos visto en El Bebedero y El Rubicón. Se han encontrado cerámicas, de las que se han analizado las pastas, fragmentos de bronce, cobre e hierro, que son, lógicamente, importados porque no hay materia prima en las Islas para poder fabricarlos, y un abalorio de vidrio"1.

10 Pablo Atoche et al. (1995), Evidencias arqueológicas del mundo romano en Lanzarote (Islas Canarias), Arrecife; Pablo Atoche Peña et al. (1999), "Pozos con cámara de factura antigua en Rubicón (Lanzarote)", VII Jornadas de Estudios sobre Lanzarote y Fuerteventura, Arrecife, 365-419.

11 Pablo Atoche Peña et al. (2006), "Excavaciones arqueológicas en el yacimiento de Buenavista (Tiagua, Lanzarote): primera campaña", Canarias Arqueológica: Arqueología / bioantropología, 17, 9-52; (2010), "Segunda campaña de excavaciones arqueológicas en el yacimiento de Buenavista (Teguise, Lanzarote): resultados preliminares", Canarias Arqueológica: Arqueología / bioantropología, 18, 1-55; Pablo Atoche (2011), "Excavaciones arqueológicas en el sitio de Buenavista (Lanzarote): nuevos datos para el estudio de la colonización protohistórica del archipiélago canario", Gerión 29, 59-82; Pablo Atoche Peña - Ma Ángeles Ramírez Rodríguez (2011), “Nuevas dataciones radiocarbónicas para la protohistoria canaria: El yacimiento de Buenavista (Lanzarote), Anuario de 


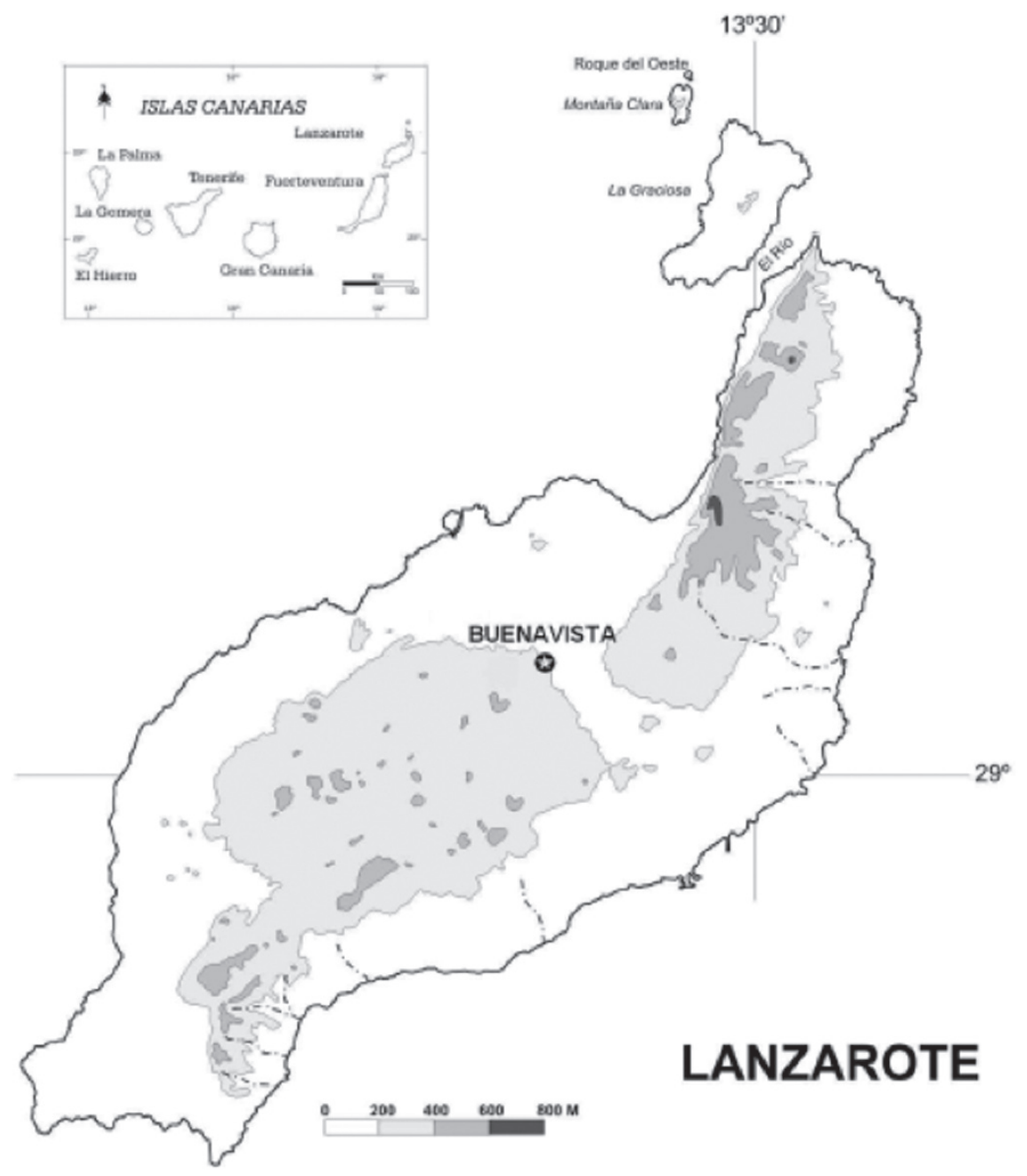

Fig. 7: Localización del yacimiento de Buenavista (tomado de Atoche - Ramírez)

Estudios Atlánticos 57, 139-170; (2017), “C14 references and cultural sequence in the Proto-history of Lanzarote (Canary Islands)", Iber-Crono. Actas del Congreso de Cronometrías Para la Historia de la Península Ibérica, Barcelona, 2017; (2017), “Gentes del ámbito cultural romano en la protohistoria de Canarias", en Germán Santana Henríquez

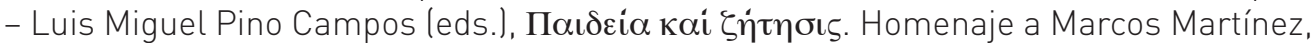
Madrid, 131-140; (2018), “El yacimiento de Buenavista, un asentamiento fenicio-púnico en Lanzarote (Islas Canarias) (circa 930-360 a.n.e.)", Actes du VIleme Congrès international des études phéniciennes et puniques, Túnez, 365-380. 
Aunque no pertenece a la época en la que están datados los yacimientos anteriores, es muy significativo el hallazgo que Francisco García Talavera realizó en La Graciosa, en la Bahía del Salado, en el cordón holoceno con una datación entre $1096 \pm 278$ y $950 \pm 277$ a.C. y que comprende un hueso de ave, otro de cabra, un trozo de cerámica a torno, numerosos restos de Thais haemastoma (machacados) y una valva de mejillón gigante Perna Perna ${ }^{12}$. Este pequeño hallazgo confirma una vez más que los contactos de las Islas con las civilizaciones mediterráneas se produjeron desde muy antiguo y con una intensidad variable en función de los intereses que en cada momento tuvieron los navegantes que se acercaban al archipiélago.

Y, por último, el yacimiento de la Isla de Lobos. Después de Lobos, poner en cuestión la vinculación de las Islas con el mundo romano no tiene sentido. El trabajo realizado por María del Carmen del Arco, María Mercedes del Arco, Carmen Benito y María Candelaria Rosario han puesto de manifiesto con gran precisión todos los elementos propios de un taller de púrpura: hay un conchero, fragmentos de caldero de plomo con restos del tinte, yunques, cerámicas de almacenaje... Todos ellos han sido analizados y datados con gran precisión y los datos estratigráficos nos confirman que el taller es contemporáneo de la época de Juba ${ }^{13}$.

Todos estos datos nos demuestran claramente la existencia de una relación duradera a lo largo del tiempo entre Canarias y la civiliza-

12 Francisco García-Talavera Casañas (2003), “Depósitos marinos fosilíferos del Holoceno de La Graciosa (Islas Canarias) que incluyen restos arqueológicos”, Revista de la Academia Canaria de Ciencias 14 (n. 3-4), 19-35; Rafael González Antón - María del Carmen del Arco Aguilar (2009), “Navegaciones exploratorias en Canarias a finales del Il Milenio a.C. e inicios del primero. El cordón litoral de La Graciosa (Lanzarote)”, Canarias Arqueológica 17 (anejo 1), 9-80.

13 María del Carmen del Arco, María Mercedes del Arco, Carmen Benito y María Candelaria Rosario (2016). Un taller de púrpura en los límites de la Ecúmene. Lobos 1 [Fuerteventura - Islas Canarias]. Primeros resultados. Tenerife, Museo Arqueológico de Tenerife. 
ción romana para la que las excavaciones nos ofrecen un periodo temporal que va desde el I a. C. al III/IV d.C.

\section{Canarias en los textos antiguos}

Veamos ahora los textos y la información que nos proporcionan. Mi intención es tratar brevemente el Periplo de Hanón; el texto de Plutarco sobre Sertorio, del que ya me he ocupado antes; luego, me quiero centrar en la descripción de Plinio; a continuación, me referiré a Mela y a Solino, especialmente en este último, quiero relacionarlo con el de Plinio, porque creo que aclara puntos que pueden ser confusos en el texto pliniano y que siempre se han traducido de una manera y que, en mi opinión, creo que se pueden interpretar de otra; luego, me ocuparé del texto de Arnobio, que es el primero en hablar de Insulae Canariae: y terminaré con el de Isidoro, con el fin de mostrar cómo la parte mítica relacionada con las Islas, vuelve otra vez a estar muy presente en la información que transmiten los autores.

\section{A. El Periplo de Hanón}

Del Periplo de Hanón ${ }^{14}$ me interesa fundamentalmente señalar que no todos los textos antiguos se refieren a Canarias, aunque sus datos se sitúen en nuestro ámbito regional. No se pueden abordar los textos desde una premisa simplista, como puede ser el hecho de que el autor se refiera a un volcán y, por tanto, el volcán será el Teide. Si partimos de esta premisa, nos vemos obligados a tener que resituar todos los datos que se mencionan en el Periplo y ello nos llevará a hacer afirmaciones erróneas desde el punto de vista geológico, por ejemplo, en la identificación de Teón Óquema.

14 Antonio Santana Santana - Trinidad Arcos Pereira (2010), “El Periplo de Hanón: una propuesta de interpretación", Latomus 69/1, 3-17. 
Durante cuatro días de travesía divisamos, por la noche, la tierra llena de llamas. En medio había una especie de hoguera, elevada, mayor que las otras, que parecía que tocaba las estrellas. De día, sin embargo, se vio que era una enorme montaña llamada Teón Óquema (Soporte/ Carro de los dioses).

Jáuregui $1^{15}$ es el primero que identifica Teón Oquema con el Teide y afirma que fondea en el Estrecho del Río, que separa Lanzarote de La Graciosa. Pero no ofrece ningún argumento para apoyar sus afirmaciones, solo se apoya en su experiencia como marino. Luego Schmitt ${ }^{16}$ y Gozalbez Cravioto ${ }^{17}$, que acepta la tesis de Schmitt, identifican Teón Oquema con el Teide, sitúan el hábitat de las mujeres velludas en Gran Canaria, el Cuerno del Sur sería el estrecho entre Fuerteventura y Cabo Jubi, y la "isla enorme" que contiene el lago de agua de mar donde se sitúa la otra isla, con una isla temporal en el istmo arenoso de Jandía, pero las distancias situadas en los mapas no corroboran estas localizaciones. Más sorprendente es que Lipinski ${ }^{18}$ en un libro reciente, que tiene aportaciones muy importantes para otras cuestiones, sitúa Teón Óquema en el Pico del Fraile, en la península de Jandía o en cualquier otra altura elevada de Fuerteventura. Esta localización es imposible por los datos geológicos, ya que las cotas de Jandía tiene entre 22 y 11,8 millones de años ${ }^{19}$, lo que es totalmente incompatible con una erupción

15 Juan José de Jáuregui (1954), "Las Islas Canarias y la carrera del oro y la púrpura en el periplo de Hannón”, en I Congreso Arqueológico del Marruecos Español (Tetuán, 1953). Tetuán, 271-276.

16 P. Schmitt (1968), "Connaissance des Îles Canaries dans l'Antiquité", Latomus 27. 362-391.

17 Enrique Gozalbes Cravioto (1993), "Algunas observaciones acerca del Periplo de Hannon”, Hispania Antiqua 17, 7-19; (2000), “Más allá de Cerné”, Eres 9, 9-42.

18 Edward Lipinski (2004), Itineraria Phoenicia, Lovaina-Paris-Dudley, MA, 435-475.

19 Instituto Geológico y Minero de España (2006), Mapa Geológico de Fuerteventura a 
en esta época, sea cual sea la datación que asignemos al Periplo. Y lo mismo sucede con todos los datos de las cotas de las alturas de Fuerteventura, que ofrecen dataciones muy antiguas. Por ello, Antonio Santana y yo hemos identificado Teón Óquema con Monte Camerún y hemos situado los principales hitos geográficos mencionados en el Periplo ${ }^{20}$. Todo ello nos ratifica nuestra posición de que a los textos no es posible acercarse desde un único punto de vista, pues estos datos son públicos y son utilizados habitualmente por los geógrafos, pero no por los filólogos.

\title{
B. El texto de Plutarco sobre Sertorio
}

Volvamos al texto de Plutarco, al que ya nos hemos referido antes.

\begin{abstract}
Allí le informaron unos marineros que habían venido hacía poco de las islas del Atlántico. Estas son dos, separadas por un estrecho muy pequeño, distan 10.000 estadios de Libia y son llamadas de los Bienaventurados. En raras ocasiones disfrutan de lluvias abundantes; la mayoría de las ocasiones disfrutan de vientos suaves y portadores de rocío; no sólo tienen una tierra fértil y buena para arar y sembrar, sino también producen frutos que crecen por sí mismos, que son suficientes por su abundancia y dulzura para alimentar sin dificultad y sin esfuerzo a un pueblo ocioso. La bonanza en las estaciones y la suavidad de su cambio son el rasgo característico de las islas. El bóreas y el apeliota, que soplan de tierra adentro y que llegan a través de la distancia a un lugar abierto, amainan y pierden fuerza; y los vientos marinos, el ábrego y el céfiro que traen del mar
\end{abstract}

escala 1:100.000, Madrid, 1 hoja y memoria; (1928-1972), Mapa Geológico de España a escala 1:50.000, "Hoja 1122-Jandía”, Madrid.

20 Antonio Santana Santana - Trinidad Arcos Pereira (2010), “El Periplo de Hanón: una propuesta de interpretación", Latomus 69/1, 3-17 (en 13-17). 
lluvias intermitentes y suaves, la mayoría de las veces refrescándolas con suaves brisas dulcemente las alimentan, de tal manera que se ha extendido hasta aquellos bárbaros la firme creencia de que allí están los Campos Elíseos y la mansión de los Bienaventurados que cantó Homero. (Plutarco, Sert. 8).

Para mí, son muy significativos los datos que señalé antes y, sobre la ruta, hay varias posibilidades para situar el origen de las distancias que señala el texto. Una posibilidad puede ser localizar el punto de partida en lol Cesarea, con una navegación costera; otra, partiría de Gades y llegaría a las islas por la ruta del Atlántico y una tercera partiría igualmente de Gades y seguiría una ruta costera que pasaría por Mogador, como puede verse en el mapa siguiente (Fig. 8).

No voy a entrar en la ruta, pero me parece que sería muy importante contar con especialistas en navegación, como va a incluir el profesor Tejera en su proyecto, porque nos pueden mostrar si es posible llegar al archipiélago por una o varias de las señaladas en el mapa.

Del texto de Sertorio se deducen tres ideas muy claras:

a) que las islas están habitadas

b) que marinos y bárbaros se entendían

c) que estos últimos tenían conocimiento de los mitos clásicos del Mediterráneo

Ello implica, por un lado, que, si están habitadas no es posible 


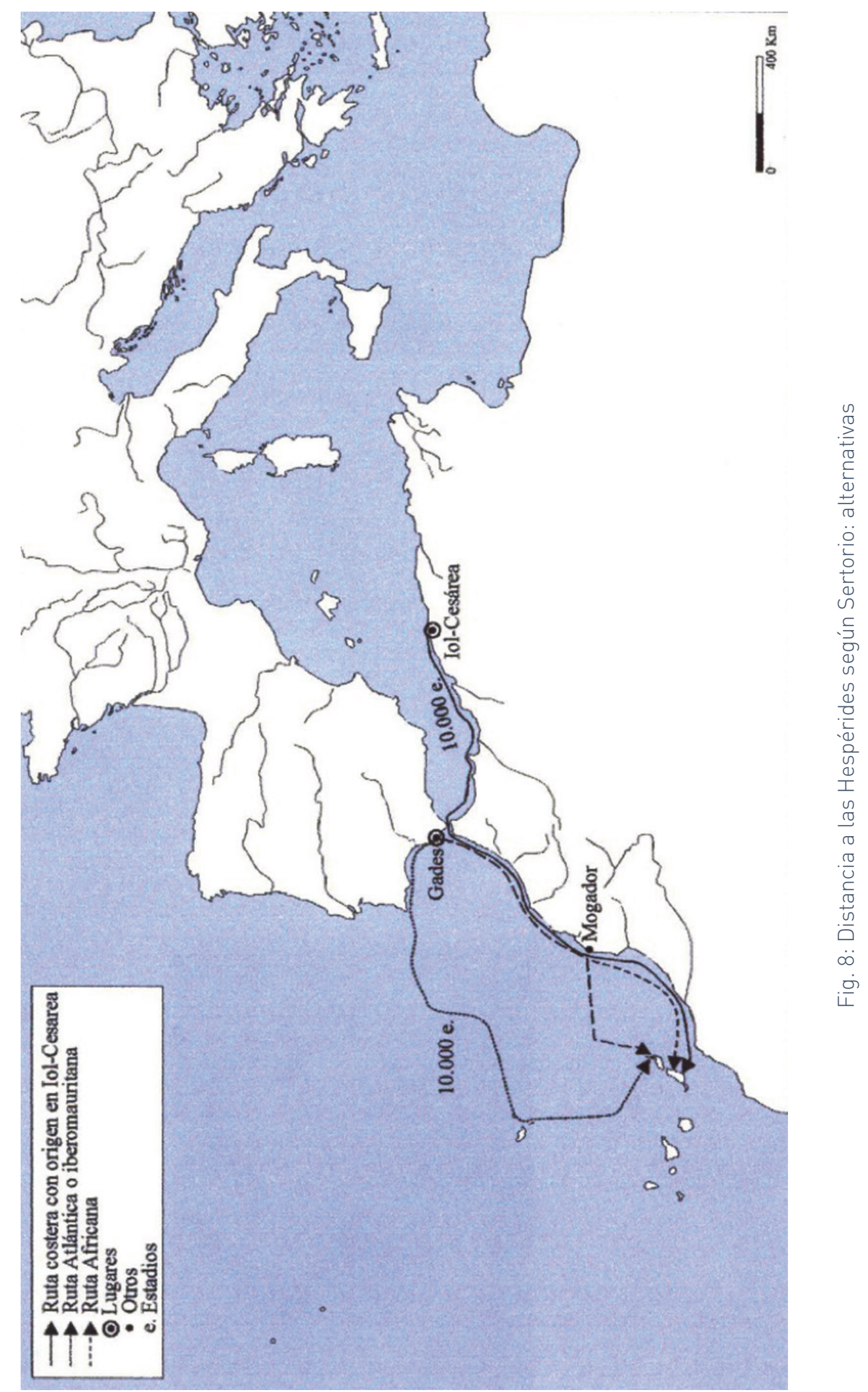


identificarlas con otras islas deshabitadas, como las Azores y, por otro, significa una relación duradera y no esporádica con los habitantes de las islas, pues se entienden con ellos y conocen los mitos clásicos del Mediterráneo ${ }^{21}$.

\section{El texto Plinio, Naturalis Historia 6.201-205}

Veamos ahora la información que nos facilita Plinio en su Naturalis Historia sobre la localización de Canarias ${ }^{22}$ :

Se cuenta que más allá de estas, están también las dos islas de las Hespérides y todo lo referente a este punto es tan incierto que Estacio Seboso dijo que desde las islas de las Gorgonas navegando por la costa frente al Atlas hay un trayecto de 40 días hasta las islas de las Hespérides y de estas a Hésperu Ceras, de un día.

\section{Las islas de Mauritania}

Y no hay una información más segura de las islas de la Mauritania. Se sabe, al menos, que unas pocas fueron descubiertas por Juba frente a los autóloles, en las cuales había decidido producir púrpura getúlica. (6.202) Hay quienes piensan que más allá de estas están las Afortunadas y algunas otras islas, de las que el mismo Seboso trasmite también la distancia diciendo que Junonia dista de Gades 750.000 pasos y desde ella, orientándose

21 Antonio Santana Santana - Trinidad Arcos Pereira - Pablo Atoche Peña - José Martín Culebras (2002). El conocimiento geográfico de la costa noroccidental de África en Plinio: la posición de las Canarias, Hildesheim - New York, 193-196.

22 Sobre la interpretación del texto de Plinio, véase Antonio Santana Santana - Trinidad Arcos Pereira - Pablo Atoche Peña - José Martín Culebras (2002), El conocimiento geográfico de la costa noroccidental de África en Plinio: la posición de las Canarias, Hildesheim - New York. 
hacia el ocaso, distan otro tanto Pluvialia y Capraria; que en Pluvialia no hay agua a no ser la de la lluvia. Desde estas, las Afortunadas están a 250.000 pasos frente a la parte izquierda de Mauritania hacia la octava hora del sol; se llaman Invale por su concavidad y Planasia por su relieve, Invale tiene un perímetro de 300.000 pasos; allí la altura de los árboles llega hasta los 140 pies.

\section{Las islas Afortunadas}

(6.203) Juba descubrió de las Afortunadas lo siguiente:

están colocadas al mediodía cerca del ocaso, a 625.000 pasos de las Purpurarias, navegando 250.000 pasos sobre el ocaso, y luego dirigiéndose al orto 375.000 pasos. La primera se llama Ombrios, que no tiene vestigios de ninguna edificación; tiene en sus montañas una laguna y árboles semejantes a la cañaheja, de los que se extrae agua, amarga de los negros, agradable de beber de los más claros. (6.204) La otra isla se llama Junonia; en ella hay sólo un templete construido con piedra. A continuación, en sus proximidades hay una menor con el mismo nombre, luego Capraria, Llena de grandes lagartos. A la vista de estas está Ninguaria, cubierta de nubes, que ha recibido este nombre de su nieve perpetua. La que está próxima a ella se llama Canaria, por la infinidad de perros de enorme tamaño - de los que le fueron entregados dos a Juba-; hay allí restos de edificaciones. Aunque en todas ellas hay abundancia de frutos y de aves de todas las especies, en esta abundan además las palmeras que producen dátiles y las piñas; hay, también, gran cantidad de miel y en sus ríos se dan el papiro y los siluros. Estas islas están infestadas de animales en estado de descomposición, que son arrojados constantemente. (Plinio 6.201-205) 
Para Antonio Santana y para mí hay en el texto datos muy importantes:

- Están situadas desde Gades y desde la parte de Mogador, y las distancias que proporciona el texto casan con las que obtenemos si las proyectamos sobre un mapa.

- Hay dos archipiélagos, no uno como lo consideramos en la actualidad: las Hespérides, Lanzarote y Fuerteventura ${ }^{23}$, y las Afortunadas, son las demás:

Hay quienes piensan que más allá de estas están las Afortunadas (Fig. 9).

La ruta plantea un problema, si seguimos el texto:

[Las Afortunadas] están colocadas al mediodía cerca del ocaso, a 625.000 pasos de las Purpurarias, navegando 250.000 pasos sobre el ocaso, y luego dirigiéndose al orto 375.000 pasos.

Las Afortunadas se sitúan a partir de las Purpurarias, que para nosotros es Mogador, navegando primero hacia el ocaso, hacia la Baja de Dacia, que es un faro natural que ofrece un punto de orientación a un marino por el distinto color que tiene el mar y una mayor afluencia de peces que atraen a aves marinas, como las gaviotas. Llegar a la Baja de Dacia supone estar en la corriente marina que lleva hasta las Islas. A continuación, el texto nos lleva hacia el orto, lo que nos llevaría al desierto africano, como puede verse en el mapa (Fig. 10).

El texto, además, no presenta variantes en la tradición manuscrita.

23 Antonio Santana Santana - Trinidad Arcos Pereira (2006), “Las dos islas Hespérides atlánticas (Lanzarote y Fuerteventura, Islas Canarias, España) durante la Antigüedad: del mito a la realidad", Gerión 24, 85-100. 


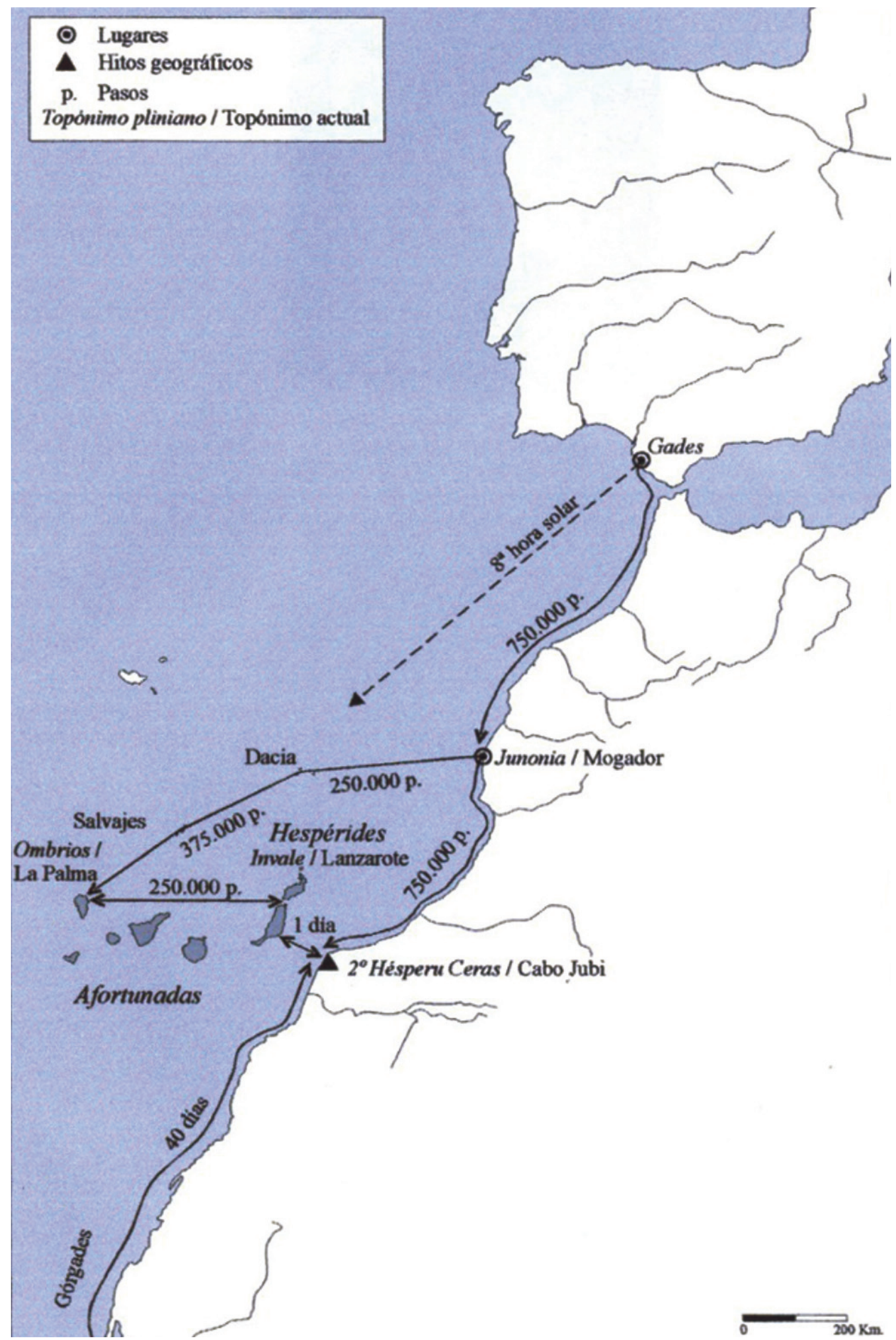

Fig. 9: Localización de las Islas Canarias en la Naturalis Historia de Plinio 


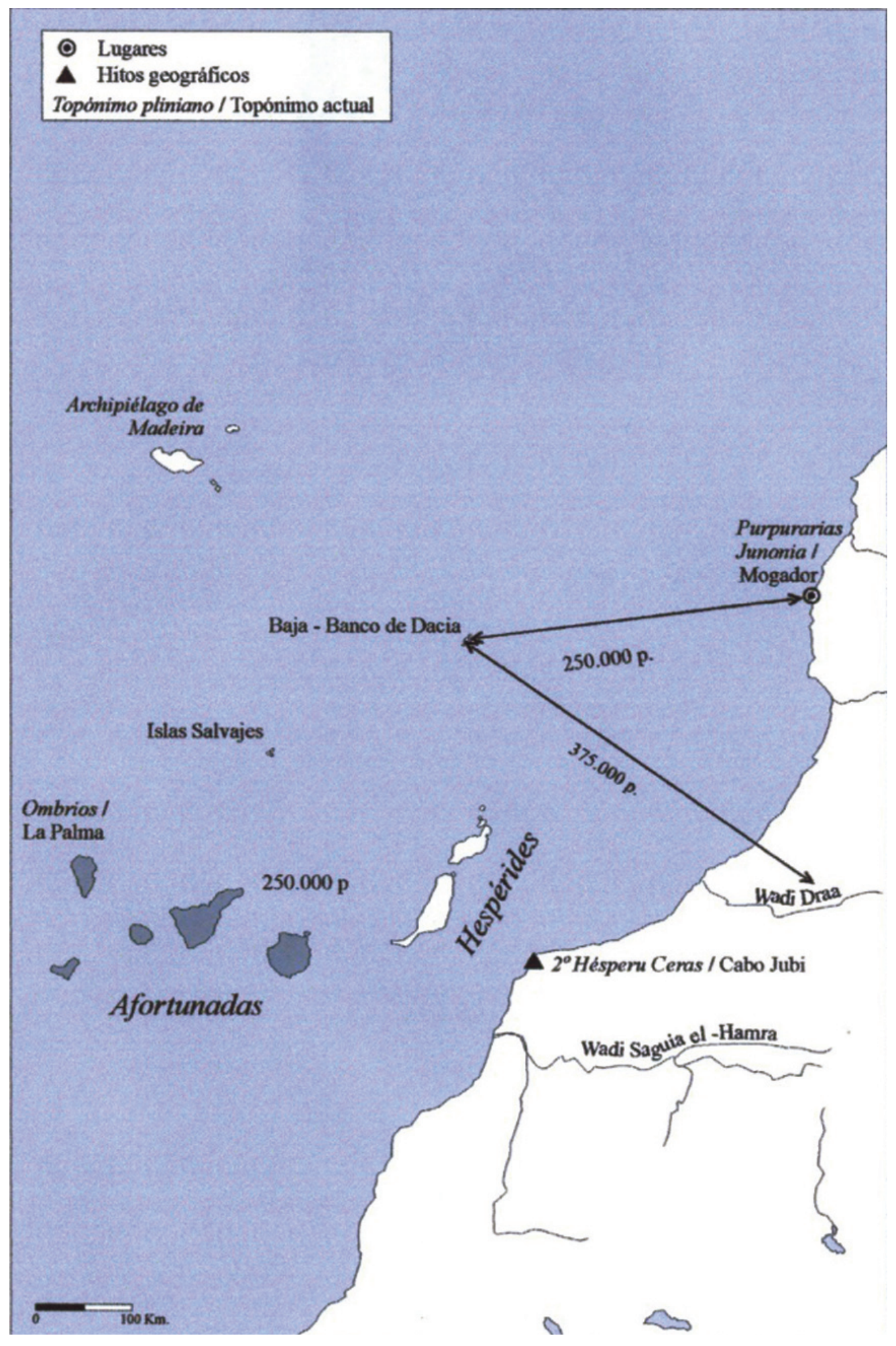

Fig. 10: Ruta "sobre el ocaso" y "hacia el orto" 
Por ello, hemos propuesto una corrección al texto pliniano, partiendo de la hipótesis de que se ha producido un error de copia en la tradición manuscrita, posiblemente motivado por una abreviatura mal entendida o por un error del copista. Así, hemos propuesto sustituir ortus por occasus de manera que la ruta nos lleva hacia La Palma, con la misma inclinación que se tiene desde Gades y con la secuencia de visitas que se señalan en el texto ${ }^{24}$ (Fig. 11).

Sobre los nombres de las islas, hay numerosas interpretaciones del texto y de la identificación de los nombres de Plinio con las islas actuales ${ }^{25}$. Desde nuestro punto de vista, la primera isla, Ombrios, sería La Palma, la primera isla que se visita.

Sobre las lunoniae, hay que tener en cuenta que el nesónimo se asigna a una isla en el confín del mundo, en el que se ha erigido un templo en honor a Juno. Por eso tenemos multitud de lunonia en todo el mundo antiguo ${ }^{26}$. El texto nos plantea otro problema, pues menciona una isla más, que no tiene nombre en el texto latino, que estaría a continuación de la lunonia y que nosotros hemos llamado Iunonia minor. Una posibilidad es que sea una isla efímera, del mis-

24 Antonio Santana Santana - Trinidad Arcos Pereira - Pablo Atoche Peña - José Martín Culebras (2002), El conocimiento geográfico de la costa noroccidental de África en Plinio: la posición de las Canarias, Hildesheim - New York, 256-273; Trinidad Arcos Pereira - Antonio Santana Santana (2004), " Plinio, nat. VI, 203: ¿Ortus u Occasus petatur?, Latomus 63/1, 137-150.

25 Los trabajos sobre la identificación de las islas son muy numerosos, entre los que podemos señalar: Juan Álvarez Delgado (1945), "Las 'islas Afortunadas' en Plinio", Revista de Historia 9, 26-61; Alberto Díaz Tejera (1988), "Las Canarias en la Antigüedad", en F. Morales Padrón (ed.), Canarias y América, Sevilla, 13-32; Antonio Tejera Gaspar (2001), “¿Qué es la Insula Capraria de Plinio?”, Faventia 23/2, 43-49; Alfredo Mederos Martín - Gabriel Escribano Cobo (2002), "Las Islas Afortunadas de Juba II. Púnicosgaditanos y romano-mauretanos en Canarias", Gerión 20/1, 315-358.

26 José A. Delgado Delgado (2001), “Las Islas de Juno: ¿hitos de la navegación en el Atlántico en época arcaica", The Ancient History Bulletin 15.1-2, 29-43; Antonio Santana Santana - Trinidad Arcos Pereira - Pablo Atoche Peña - José Martín Culebras (2002), El conocimiento geográfico de la costa noroccidental de África en Plinio: la posición de las Canarias, Hildesheim - New York, 297-298. 


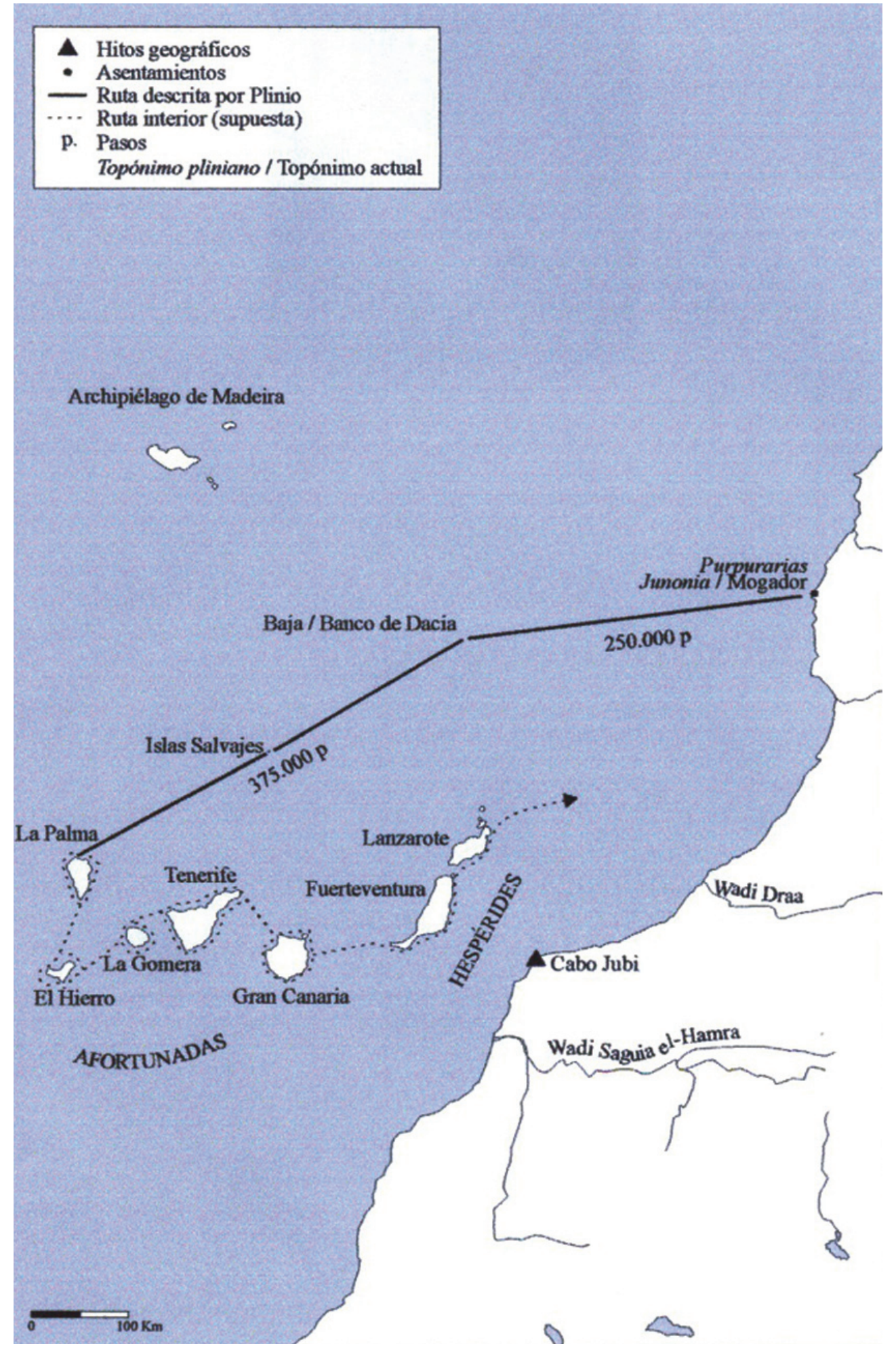

Fig. 11: Ruta de la expedición de Juba II "hacia el ocaso" 
mo tipo que la que hubiéramos podido tener en la última erupción del Hierro, si esta hubiera sido más prolongada e intensa y que habría desaparecido con el tiempo porque no tiene suficiente base para permanecer. Este tipo de islas efímeras están documentadas en la Antigüedad en el mismo texto de Plinio que nos señala que en algunos lugares hubo una isla que desapareció ${ }^{27}$.

Ninguaria es sin duda Tenerife. Hay autores que piensan que no puede haber nieve en esa época del año, pero posiblemente se deba a que estén pensando desde el prisma del clima que tenemos actualmente, no con el que probablemente habría en aquel tiempo. Si los autores antiguos dicen que la banquisa polar llega hasta las Casitérides, es decir, que está tan próxima a Islandia, hay que entender que el clima es mucho más frío. Por eso, el que haya nieves perpetuas en el momento de la expedición no nos plantea ningún problema ${ }^{28}$. Hay también discusión sobre cómo la evolución del nombre a Nivaria, pero Alberto Díaz Tejera resolvió este problema en su artículo sobre Canarias en la Antigüedad ${ }^{29}$.

Es evidente que Canaria es Gran Canaria. Es la única isla que conserva su nombre desde la Antigüedad, es la que da, luego, el nombre al archipiélago. Se discute si se la denomina así por perro o por

27 Antonio Santana Santana - Trinidad Arcos Pereira - Pablo Atoche Peña - José Martín Culebras (2002). El conocimiento geográfico de la costa noroccidental de África en Plinio: la posición de las Canarias, Hildesheim - New York, 298-304.

28 Antonio Santana Santana - Trinidad Arcos Pereira - Pablo Atoche Peña - José Martín Culebras (2002). El conocimiento geográfico de la costa noroccidental de África en Plinio: la posición de las Canarias, Hildesheim - New York, 307-308.

29 Alberto Díaz Tejera (1988), "Las Canarias en la Antigüedad", en F. Morales Padrón (ed.), Canarias y América, Sevilla, 13-32. 
lobos marinos ${ }^{30}$. Tenemos un problema para aceptar que el nombre se remita a la abundancia de lobos marinos, porque el nombre para lobo marino es distinto en latín, en esta época están muy extendidos y no se puede sostener que un marino, que conocería bien la especie, lo denomine canes. Por otro lado, hay que señalar un aspecto referido a la traducción que generalmente se da de este este fragmento, porque se suele añadir algo que no está en el texto. Lo que encontramos en él es: "Estas islas están infestadas de animales en estado de descomposición, que son arrojados constantemente". No habla de animales marinos y en el texto no hay ninguna mención a que estos sean arrojadas por el mar, que es la traducción habitual de este texto. Debemos, pues, acostumbrarnos a tener en cuenta solo lo que está en los textos y, por eso, en mi traducción he suprimido todo aquello que no está en él, porque nosotros podemos interpretar y deducir a partir de ellos, pero no podemos decir que lo afirme Plinio ${ }^{31}$.

Otra cuestión que plantea el texto es el de la doble toponimia para dos islas: Invallis/Pluvialia y Capraria/Planasia. En nuestra opinión, creemos que hay una mezcla de fuentes y que Plinio las ha recogido en su texto. Para nosotros, Invallis/Pluvialia es Lanzarote y Capraria/Planasia es Fuerteventura; nuestra hipótesis se basa en el hecho de que Plinio por su cargo tenía a su disposición fuentes que no eran accesibles a otros autores entre las cuales debían de estar los textos de navegaciones fenicias que los romanos se llevaron de Cartago después de las Guerras Púnicas, de la misma manera que

\footnotetext{
30 Hay que mencionar también otras hipótesis sobre el origen del nombre de Canaria: del pueblo del norte de África, los canarii, de canna, nombre genérico que engloba a las Euphorbias; de cananeo (fenicio); de canaani, que se leería como cananeo; de gannari, término que hace alusión a Cabo Jubi y a los gannari del reino de Ganar... Antonio Santana Santana - Trinidad Arcos Pereira - Pablo Atoche Peña - José Martín Culebras (2002), El conocimiento geográfico de la costa noroccidental de África en Plinio: la posición de las Canarias, Hildesheim - New York, 298.

31 Antonio Santana Santana - Trinidad Arcos Pereira - Pablo Atoche Peña - José Martín Culebras (2002), El conocimiento geográfico de la costa noroccidental de África en Plinio: la posición de las Canarias, Hildesheim - New York, 309-317.
} 
lo hicieron con los textos agrícolas ${ }^{32}$. De las características de ambas, llama la atención la mención a la existencia de árboles de alto porte, que llegan a alcanzar 140 pies en Invallis/Pluvialia. Este dato, que sorprende por el paisaje actual de Lanzarote, ha sido confirmado por las excavaciones que han encontrado restos de árboles de elevada altura; y no podemos obviar el intenso proceso de deforestación que han sufrido las Islas, especialmente las orientales a lo largo de toda la historia ${ }^{33}$.

En el texto se menciona que en Canaria había siluros y papiro, y se ha apuntado la posibilidad de que el copista se hubiera equivocado y se refiriera en realidad a sileres ${ }^{34}$. Desde la perspectiva de la transmisión manuscrita es muy difícil mantener que pueda haber escrito una 'e' por una 'u'. En cuanto a la mención del papiro, hay que señalar que Plinio sólo señala su existencia en el Nilo, en el Éufrates, en Gran Canaria y en el Níger. La mención a la presencia de miel es, también, significativa, porque es un signo de antropización, pues su producción siempre ha acompañado al hombre y, si en ese momento, la isla está deshabitada, su presencia nos indicaría que ha habido algún tipo de habitación en ella, lo que estaría corroborado por los restos de edificaciones que se menciona en la

32 Antonio Santana Santana - Trinidad Arcos Pereira - Pablo Atoche Peña - José Martín Culebras (2002), El conocimiento geográfico de la costa noroccidental de África en Plinio: la posición de las Canarias, Hildesheim - New York, 190-193.

33 Antonio Santana Santana - Trinidad Arcos Pereira - Pablo Atoche Peña - José Martín Culebras (2002), El conocimiento geográfico de la costa noroccidental de África en Plinio: la posición de las Canarias, Hildesheim - New York, 222-225.

34 Alicia María García García apuntaba esta posibilidad en su tesis (Alicia María García García (2007), Juba II, rey de Mauritania: traducción y comentario de sus fragmentos, Tesis doctoral presentada en la Universidad de La Laguna, 256). En trabajos posteriores, ha matizado su posición y señala que no es posible corroborar la presencia de "siluros y papiros", porque es aventurado determinar que hubiera peces en los barrancos canarios, aunque fueran caudalosos (Alicia María García García, 2007, “Una aproximación al texto 202-205 del libro VI de Plinio el Viejo sobre las Fortunatae Insulae", Fortunatae 18, 19-41; 2009, "El informe de Juba II sobre las Fortunatae Insulae (Plinio el Viejo, HN, VI, 202-205)", Revista Tabona 17, 141-164). 
descripción. En este mismo sentido, si los canes fueran realmente perros, su existencia apoyaría esta presencia humana, porque siempre son animales introducidos por el hombre.

Nuestra propuesta para la ruta, que denominamos ruta norte o iberomauritana', es la que se puede ver en el mapa (Fig. 12).

Es coherente que se inicie en Ombrios/La Palma, porque desde esta isla se pueden tomar mediciones para las islas, deben desplazarse hacia el este, porque Niguaria/Tenerife impide la visión de Canaria/ Gran Canaria y, aunque no está en el texto, es posible conjeturar que se establecieran dos bases en Ombrios/La Palma y en Canarial Gran Canaria, porque son las dos islas mejor descritas ${ }^{35}$. En cuanto a la ruta de vuelta, es posible que se hiciera por navegación de cabotaje, porque por las corrientes es imposible volver por la misma ruta de acceso.

El texto nos proporciona una localización precisa de las Islas, con referencia a Gades, Mogador y las Hespérides, con distancias que pueden ser trasladadas a un mapa con escaso margen de error (Fig. 13).

Como ya hemos mencionado, el texto ofrece detalles del paisaje de las islas, más precisos de Ombrios/La Palma y de Canaria/Gran Canaria. Uno de los elementos que se mencionan es una laguna en Ombrios, que en la actualidad no existe. Pero si consultamos los registros geológicos de la Caldera hay en un momento determinado un deslizamiento que obstruye temporalmente la evacuación del agua de la Caldera y forma una laguna en Risco Liso, donde ahora está la Playa de Taburiente. También hay que señalar las dos

35 Antonio Santana Santana - Trinidad Arcos Pereira - Pablo Atoche Peña - José Martín Culebras (2002), El conocimiento geográfico de la costa noroccidental de África en Plinio: la posición de las Canarias, Hildesheim - New York, 283-287. 


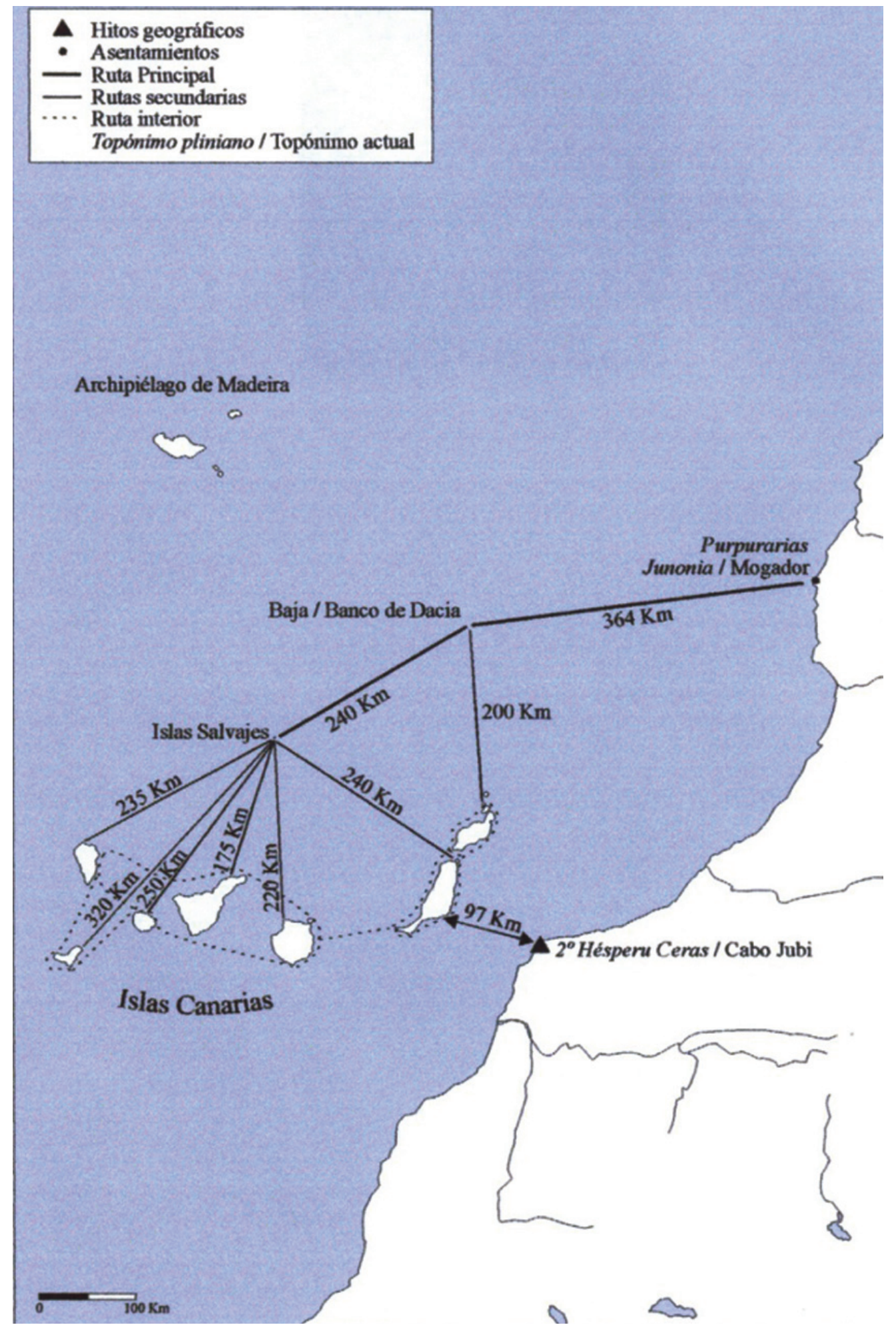

Fig. 12: Ruta norte o iberomauritana a las Canarias 


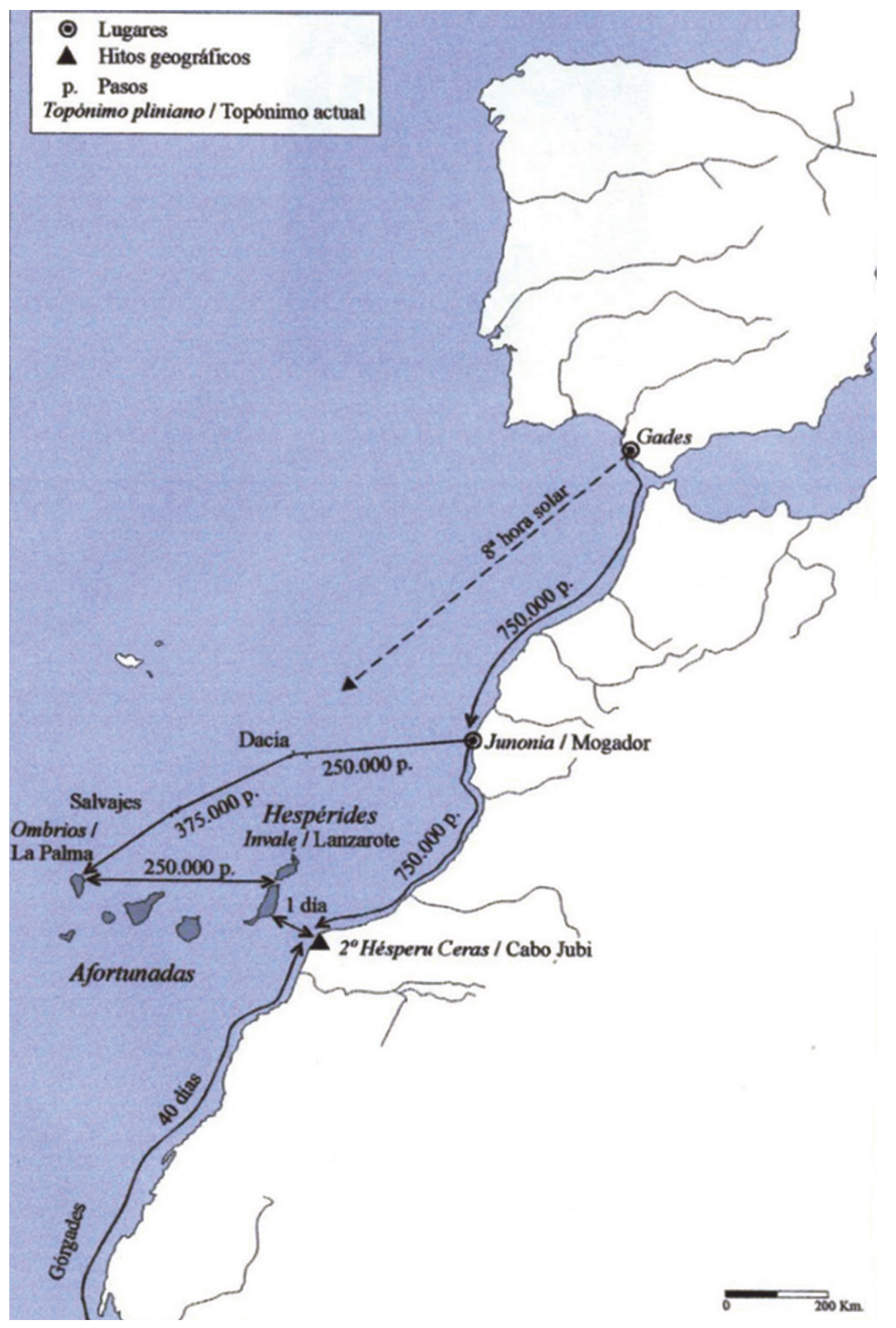

Fig. 13: Localización de las Islas Canarias en la Naturalis Historia de Plinio 
cañahejas, de las que se extrae agua, de una amarga, de la otra, una más agradable de beber y de las que hablaremos más adelante, cuando veamos el texto de Mela ${ }^{36}$. Podemos ver un resumen de esta descripción en la siguiente ilustración (Fig. 14).

Un aspecto al que también se debe prestar atención es el contexto histórico en el que se realiza la exploración. Por un lado, parece evidente que Juba II pudo tener interés en delimitar la extensión de su reino y conocer los recursos de los que disponía. Pero, al mismo tiempo, creemos que es posible relacionarla con la elaboración del Mapa de Agripa y de todas las exploraciones que se llevan a cabo en esta época y que debieron de contribuir al posterior cambio del meridiano cero a las Afortunadas ${ }^{37}$, que utilizará Marino de Tiro por primera vez, seguido más tarde por Ptolomeo.

Un último dato que ofrece el texto es el de que las islas "están a la izquierda de Mauritania" y ello solo puede suponer que se está mirando un mapa norteado, no podemos saber si es el Mapa de Agripa u otro, pero podríamos deducir que Plinio tendría ante sus ojos un mapa con la situación de las islas frente a África, dato que luego repetirán los autores posteriores que traten sobre Canarias.

36 Antonio Santana Santana - Trinidad Arcos Pereira - Pablo Atoche Peña - José Martín Culebras (2002). El conocimiento geográfico de la costa noroccidental de África en Plinio: la posición de las Canarias, Hildesheim - New York, 289-297.

37 Antonio Santana Santana - Trinidad Arcos Pereira - Pablo Atoche Peña - José Martín Culebras (2002), El conocimiento geográfico de la costa noroccidental de África en Plinio: la posición de las Canarias, Hildesheim - New York, 232-244; Antonio Santana Santana - Trinidad Arcos Pereira (2003-2007), "La expedición de Juba II a las Islas Afortunadas y el meridiano cero del Orbis Terrarum", Orbis Terrarum. Internationale Zeit-zchrift für Historische Geographie der Alten Welt 9, 143-158. 


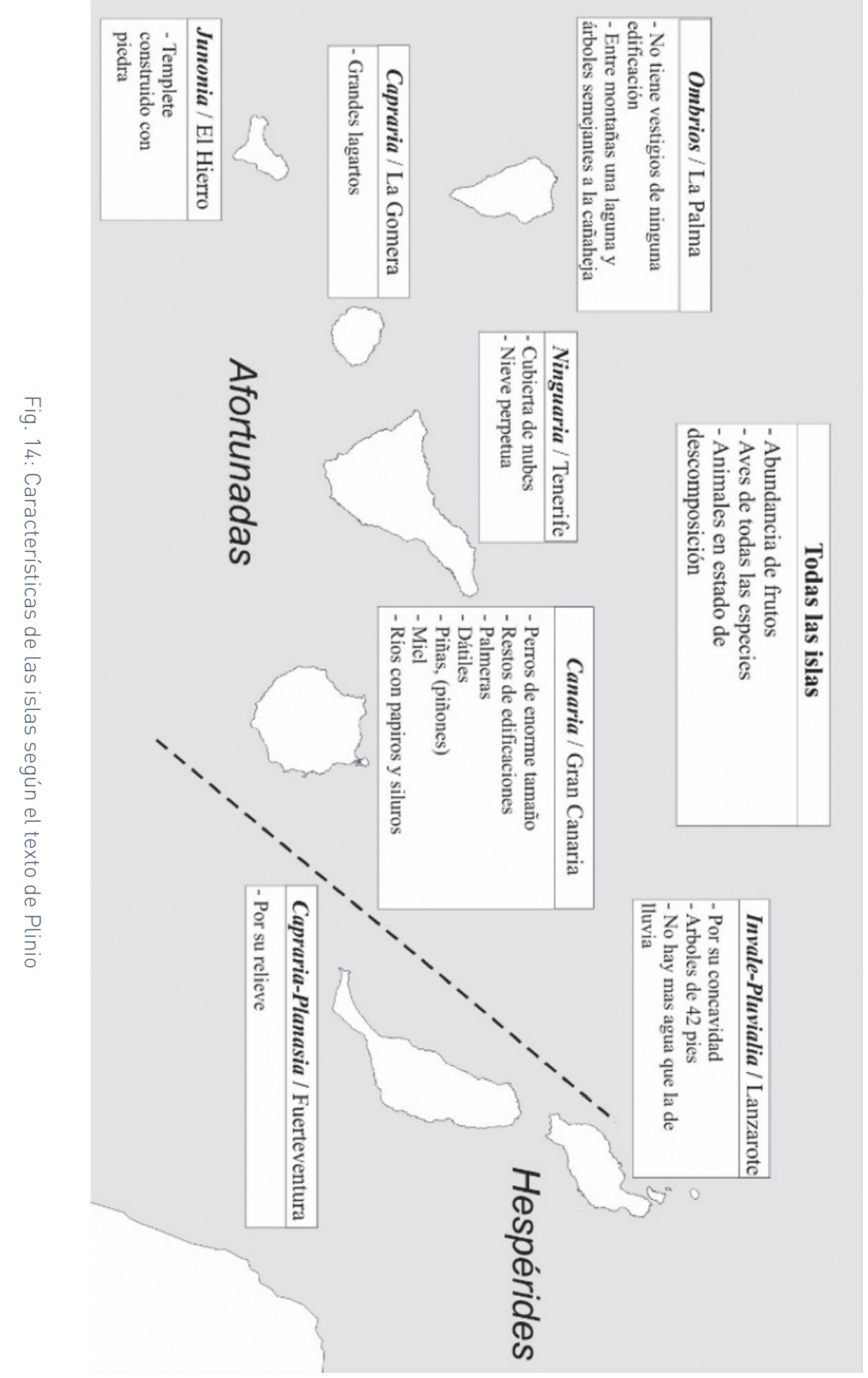




\section{El texto de Pomponio Mela}

De Mela siempre se ha afirmado que toma sus datos de la Naturalis Historia de Plinio, pero hay que tener en cuenta que el texto de la Corographia se termina antes de la obra pliniana. Por ello, parece más razonable considerar que ambos utilizaran la misma fuente y no que uno de ellos tenga como fuente al otro.

Después empieza aquel frente costero que, volviéndose a Occidente, es bañado por el mar Atlántico: sus primeras tierras las habitan los etíopes; las de en medio nadie, pues o están abrasadas o cubiertas por las arenas o infestadas de serpientes. Próximas a las tierras abrasadas se encuentran unas islas en las que se dice que vivieron las Hespérides (Mela, Corographia 3.100)

Frente [al Atlas] las islas Afortunadas son abundantes en frutos que nacen espontáneamente y que crecen sin cesar, con los alimentan a los que viven sin preocupaciones, más felices que otras ciudades civilizadas. Una es muy famosa por la singular naturaleza de dos fuentes: Los que han probado una mueren de risa, así para los afectados por este mal el remedio es beber de la otra. (Mela, Corographia 3.102).

En el texto aparecen, de nuevo, las Hespérides y las Afortunadas como islas diferentes, de estas últimas señala que están situadas frente al Atlas y se las describe de nuevo con rasgos de un locus amoenus. Concluye la descripción de las Afortunadas con la mención a dos fuentes; si, como hemos visto antes, en Plinio teníamos en la isla de Ombrios dos árboles semejantes a las cañahejas, uno del que se extrae agua amarga y del otro, agua más agradable de beber, en Mela vamos a tener dos fuentes. Ello nos puede llevar a 
pensar en una diferente interpretación de la fuente original o en que esta contenía la mención a las fuentes y a las cañahejas cada uno tomó lo que le pareció más relevante. No podemos dejar de poner en relación estos datos con los análisis que se han realizado en la Caldera de Taburiente que tiene aguas completamente insalubres y con efecto purgante, y otras, en cambio, que son potables ${ }^{38}$.

\section{E. El texto de Solino}

Cayo Julio Solino vivió en el siglo III o IV d.C., pues hay dudas sobre las fechas en las que vivió. Escribió De mirabilibus mundi, obra en la que recoge maravillas del mundo con una gran influencia de Plinio y de Mela.

Hemos oído decir que las islas Afortunadas ciertamente yacen frente a la parte izquierda de Mauritania, de las que Juba dice que están situadas hacia el sur, pero próximas al ocaso. [...]

También cuentan que se arrojan animales en el ondulante mar y que, luego, cuando aquellos monstruos se han fundido con la pobredumbre, todo allí se impregna de un olor repugnante, por lo que la calidad de las islas no está del todo de acuerdo con su nombre. (Solino, De mirabilibus mundi 56,13-19)

En su texto sobre las islas Afortunadas, Solino vuelve a señalar que están frente la parte izquierda de Mauritania, bien porque toma el dato de Plinio o porque también él tiene presente un mapa en su descripción. Remite a Juba para situarlas hacia el sur y próximas

38 Antonio Santana Santana - Trinidad Arcos Pereira - Pablo Atoche Peña - José Martín Culebras (2002), El conocimiento geográfico de la costa noroccidental de África en Plinio: la posición de las Canarias, Hildesheim - New York, 293. 
al ocaso, lo que sería un apoyo a nuestra corrección del texto de Plinio, ya que las sitúa al ocaso y no al orto. También apoya nuestra decisión de no seguir la traducción habitual del texto de Plinio, pues no es el mar el que arroja los animales, sino que se arrojan a él. Por ello, los textos no deben ser estudiados de manera aislada, sino estableciendo una interrelación de los datos que nos ofrecen.

Hay que destacar también que Solino también pone en cuestión el carácter idílico de las islas al enfrentar el topónimo con la situación que provoca la descomposición de los animales arrojados al mar.

\section{F. El texto de Arnobio}

Arnobio de Sicca es un autor cristiano que vive entre finales del siglo III y principios del IV d.C. (muere en el 330 d.C.). Para mostrar la sinceridad de su conversión al cristianismo, escribe Aduersus nationes, una apología del cristianismo.

Y si no es así, se quita toda esperanza de ayuda y habrá la duda de si somos oídos por los dioses o no si alguna vez realizáis las ceremonias sagradas a los que se les debe. Para saberlo, decidamos que haya un templo en honor a un dios en las Islas Canarias, al mismo dios en la última Thule; a ese mismo en el País de los Seres, entre los negros garamantes, y si hay algún otro, al que mares, montes, bosques y los cuatro puntos cardinales separe de su propio conocimiento. (Arnobio, Aduersus nationes 6.5)

El texto de Arnobio es muy conocido por ser el primero que nombra a las Islas como Insulae Canariae. El autor está señalando los hitos geográficos que delimitan los confines del mundo conocido: Thule, 
el País de los Seres, los negros garamantes y las Islas Canarias, que fija el límite del mundo conocido en occidente.

\section{G. El texto de Isidoro de Sevilla}

Isidoro de Sevilla fue un autor hispano que vivió entre c. 556 y 636 d.C., fue arzobispo de Sevilla y se le considera uno de los Padres de la Iglesia. Escribe sus Etymologiae como un compendio del conocimiento de su época y su obra será muy utilizada a lo largo de la Edad Media.

Las islas Afortunadas nos están indicando con su nombre que producen toda clase de bienes; como si se las considerara felices y dichosas por la abundancia de sus frutos. De manera espontánea producen frutos los más preciados árboles; las cimas de las colinas se cubren de vides sin necesidad de plantarlas, nacen por doquier mieses y legumbres. De ahí el error de los gentiles y de los poetas paganos, según los cuales, por la fecundidad del suelo, aquellas islas eran el Paraíso. Están situadas en el océano, enfrente y a la izquierda de Mauritania, cercanas al occidente de esta, separadas entre sí por el mar que las circunda (Isidoro, Etymologiae 14,6,8-9)

Las Islas se han abandonado después de la crisis del siglo III-IV d.C. y la descripción de Isidoro refleja ya que no forman parte del mundo conocido, sino que está impregnada de la visión mítica que relaciona el archipiélago con el Jardín de las Hespérides y las Islas de los Bienaventurados. Solo al final, encontramos ecos de los textos de Plinio y de Solino: "Están situadas en el océano, enfrente y a la izquierda de Mauritania, cercanas al occidente de esta, separadas entre sí por el mar que las circunda". De esta manera, Isidoro recoge su localización a la izquierda de Mauritania y cercanas al ocaso. 
Como hemos podido mostrar, los textos antiguos son textos reales y ofrecen datos muy relevantes sobre Canarias a lo largo de la Antigüedad. Están unidos a una tradición mítica, que asocia a las Islas a mitos de tanta relevancia como las islas de las Hespérides o las de los Bienaventurados. Por ello, hay que estudiarlos de una forma conjunta, no se pueden abordar con la mentalidad de ahora, sino que deben ser contextualizados en el momento en que se escriben y no pueden ser analizados desde un único punto de vista, sino que es necesario una visión interdisciplinar desde la Filología, la Arqueología, la Geografía y los conocimientos marinos.

\section{La descripción de Canarias en el Humanismo}

En el Renacimiento, las Islas se conocen por algunas informaciones transmitidas por los árabes, por las expediciones italianas del siglo XIV y, desde comienzos del siglo XV, cuando Jean de Bethencourt y Gadifer de la Salle obtienen del rey de Castilla, Enrique III, los derechos para conquistar las Islas y llegan a Lanzarote y Fuerteventura. Al mismo tiempo, la recuperación de los textos clásicos que llevan a cabo los humanistas proporcionaran, junto a la obra de Plinio y de los geógrafos antiguos, una visión mítica de Canarias, ligada, como hemos visto, al Jardín de las Hespérides, las Islas de los Bienaventurados, etc. Por ello, vamos a encontrar entre los humanistas información real de las Islas y, por otro, la descripción mítica que enlaza con los mitos que hemos mencionado. Veamos cuatro textos: uno de las Rerum a Fernando \& Elisabe Hispaniarum felicissimis Regibus gestarum Decades duae, de Antonio de Nebrija (1441-1522), y otro del De rebus Hispaniae memorabilibus de Lucio Marineo Sículo (1444-1536), que pertenecen al siglo XV y comienzos del XVI, que van a recoger información real, vinculada a la conquista de las Islas; y otros dos, uno de las Variae lectiones de Marc-Antonie Muret (1526-1585) y otro de la Epaenesis Iberica de Luis Tribaldos de Toledo (1558-1634), posteriores a Nebrija y a Marineo Sículo, que van a describir las Islas desde una perspectiva 
literaria y mítica sin tener en cuenta la información real con la que se contaba ya en el siglo XVI-XVII.

\section{A. El texto de Antonio de Nebrija}

Antonio de Nebrija escribe su Rerum a Fernando \& Elisabe Hispaniarum felicissimis Regibus gestarum Decades duae, después de su nombramiento como cronista del rey Fernando, sin llegar a completarla antes de su muerte, por lo que es publicada por su hijo en 154539. En la Decada segunda, se ocupa de la descripción de las Canarias:

... Ahora debemos decir unas pocas cosas sobre las [islas] cercanas a la costa occidental de África, entre las que se encuentran las Canarias, [...]. Plinio, en su Historia Natural, es el autor de que las Canarias fueron llamadas así por el gran tamaño de los perros, de los cuales el rey Juba se llevó dos de este género. Fueron llamadas Afortunadas por los griegos, de las que tanto poetas como historiadores dicen muchas cosas fabulosas que se refieren muy poco a este lugar. Ptolomeo, Marciano, Plinio y otros autores, tanto griegos como latinos, explican sus nombres, pero con ellos no podemos restituir los nombres con las que se designan en nuestro tiempo. Pues también los antiguos las conocieron y dejaron por escrito su entorno y las costumbres de sus habitantes. Pero por qué motivo se borró su celebridad de la memoria de los hombres, se desconoce. Es posible creer que ello sucedió por el cese de la navegación. Lo que verdaderamente nos consta es que la noticia de aquellas islas ha llegado a nosotros, desde este momento, hace aproximadamente unos ciento veinte años, al inicio del reinado de Juan, segundo de este nombre, que

39 Matilde Conde Salazar (1992), "Introducción" a Antonio de Nebrija, Cerco al reino de Granada, Madrid, UNED, 6-7. 
empezó a reinar bajo la tutoría de su madre Catalina y su tío Fernando, en el año 1405 de la era cristiana. (Antonio de Nebrija, Rerum a Fernando \& Elisabe Hispaniarum felicissimis Regibus gestarum Decades duae, traducción de Marcos Martínez).

Como puede verse en el texto, remite como fuente a Plinio, del que solo recoge el origen del nombre de Canaria a partir de los perros, de los que fueron llevados dos a Juba. Omite, sin embargo, todos los demás datos. Señala el nombre dado por los griegos de Afortunadas y la incongruencia existente entre este nombre y la descripción de los poetas y la realidad de la vida en las Islas en ese momento. Afirma que es imposible restituir los nombres actuales con los que se encuentran en los textos antiguos y apunta a que su existencia se olvidó por el cese de la navegación. A continuación, se centra en el momento en el que se vuelve a tener noticias de ellas en su época en el reinado de Juan II.

Estamos, pues, ante un texto histórico, en el que Nebrija se hace eco del conocimiento sobre las Islas que el Humanismo había recuperado de los textos antiguos, especialmente de Plinio, pero es apenas una introducción para centrarse en la conquista de Canarias que se completa en el reinado de los Reyes Católicos y de la que proporciona datos obtenidos por los castellanos. Estas noticias de Canarias son el preámbulo de Nebrija a la conquista del reino de Granada.

\section{B. El texto de Lucio Marineo Sículo}

Lucio Marineo Sículo, humanista italiano que fue profesor de la Universidad de Salamanca y cronista del rey Fernando de Aragón. Publica sus De rebus Hispaniae memorabilibus libri XXV en Alcalá de Henares en 1530 y en su libro XIX escribe sobre la conquista de las Islas Canarias a instancias de los Reyes Católicos. 
[Los Soberanos católicos] Enviaron después una gran flota a las Islas Canarias y muchas naves cargadas de armas, caballos, víveres y todas las cosas necesarias para navegar y hacer la guerra. [...] Pues los canarios, aunque carecían de armas y de hierro, usaban, sin embargo, dardos hechos de las ramas de los árboles, que aguzaban con piedras muy afiladas, con los cuales, como con dardos de hierro muy agudos, fácilmente traspasaban las adargas y escudos. Lanzaban piedras, además, muy fuertemente, pues sin duda eran valientes, de grandes fuerzas y hombres de pelea y animosos, los cuales salían de cuevas, que hay muchas entre ellos, así como de fortalezas, y peleaban con fiereza. [...] Su tierra es muy cálida y muy fructífera, abundante en ganados, mayormente domésticos. Hay allí gran cantidad de miel y de muchas cosas necesarias para la vida humana. Los hombres no son de color blanco ni negro, tienen la nariz ancha y llana y son de agudo ingenio. Vestíanse no de lana ni de lino, sino únicamente de pieles de animales. Comían raíces de hierbas, leche y carne de cabras, además de frutas de árboles y de la tierra. Tenían casas de ramas de árboles y cuevas en las que se protegían de los calores del sol y de las lluvias. Labraban la tierra con cuernos de bueyes y con mayor trabajo que cultivo cogían mucho fruto. Adoraban a un solo dios, alzadas las manos al cielo. Tenían un cierto y determinado lugar para orar, al que rociaban cada día con leche de cabras. Tenían apartadas las cabras con cuya leche hacían esto y las llamaban animales santos. Tenían lengua bárbara, que ellos solos entre sí entendían. [...] Por lo demás, estas islas del Atlántico, que Plinio y otros escritores llaman Afortunadas, son siete y paréceme que si las nombramos no será una cosa ingrata: Obrion, que Plinio llama Ombrión, sin señales de edificios, tiene en los montes un estanque y árboles como cañahejas de los cuales sale agua; de los que son negros, amarga, y de los blancos dulce y buena de beber; Junonia, en la cual había casitas hechas de piedra; 
Pluvialia, que no tiene agua sino las de la lluvia; Capraria, que está infectada de grandes lagartos; Planaria, que tiene llanuras y valles; Nivaria, a la cual Plinio llama Ningaria por la continua nieve y niebla. Cerca de esta está Canaria, dicha así por la multitud y tamaño de los perros. Si bien todas las otras son abundantes en frutas y en todo género de aves, esta sola se vanagloria de palmeras que producen dátiles. Abunda también en pinares, nogales y mucha miel. Tiene asimismo peces siluros y papiro en los ríos. (Lucio Marineo Sículo, De rebus Hispaniae memorabilibus libri XXV, 19.15, traducción de Marcos Martínez).

Su texto, como el de Nebrija, recoge la conquista y ofrece datos sobre sus habitantes. Pero también incluye el texto de Plinio, sintetizando la información de las Hespérides y las Afortunadas. Así nombra Ombrios, Nivaria lya con el nombre evolucionado, aunque menciona el antiguo Ninguaria), Iunonia, Capraria, Canaria, Planaria y Pluvialia y suprime Invallis y la isla menor que estaba cerca de lunonia, para dar coherencia al texto de Plinio e intentar relacionarlo con los conocimientos que se tienen ya de las Islas en su época.

Los textos siguientes son muy diferentes, pues describen al archipiélago obviando cualquier referencia al conocimiento real que se tenía de ellas en el siglo XVI.

\section{El texto de Marc-Antoine Muret}

Marc-Antoine Muret fue un humanista francés que vivió en el siglo XVI (1526-1585). Profesor en Francia y en Italia, escribió numerosas obras entre las que se encuentran sus Variae lectiones, que se conservan en un manuscrito de la Biblioteca Nacional en las que se incluye una descripción de las Fortunatarum Insulae: 
Se ha transmitido en los antiguos poetas que hay en el Océano unas islas a las que después de la muerte son llevadas las almas de los que han vivido santa y religiosamente; allí gozan de una vida grata y deliciosa en un prado agradabilísimo, que está adornado y cubierto con una preciosa variedad de las flores más gratas a la vista y al olfato. Allí siempre brilla el cielo, están cubiertos de hojas los árboles, crece la hierba, todo ríe, soplan continuamente suavísimos favonios, con cuya brisa, las copas de los árboles, suavemente mecidas, acarician los oídos con un dulcísimo murmullo. Llega allí una innumerable cantidad y variedad de avecillas inmortales que, difundiendo siempre clarísimos cantos con dulce garganta, halagan con increíble placer, la profunda sensibilidad de los que las oyen. El mismo prado está recorrido en varios lugares por riachuelos de caudal constante, cuya agua clarísima, detenida suavemente su corriente y retenida junto a piedrecillas que cambian de color, produce un dulcísimo murmullo. De esta manera, allí con la suavidad de las florecillas que exhalan olor de ambrosía, allí con el soplo de los Céfiros que juegan con las ramas verdeantes de los árboles, allí con el concierto de los pájaros, allí con el ligero murmullo de los riachuelos susurrantes aquellas mentes ríen siempre felices. Pues unos bailan al son de la lira de Orfeo o de Anfión, otros tocan la cítara, otros tejen coronas, otros echados en la hierba, por donde la tierra se oscurece con las trémulas sombras de los laureles y de los mirtos, tienen agradabilísimas conversaciones. La tierra misma, rica en recursos propios, sin cultivo alguno, tres veces al año, con la mayor fertilidad, les proporciona y les ofrece abundancia de alimentos. (Muret, Variae Lectiones, traducción de Trinidad Arcos Pereira y María Elena Curbelo Tavíol

Marc-Antoine Muret ofrece una imagen mítica de las Fortunatarum Insulae, en la que no hay ninguna referencia a las Islas Canarias que 
se conocen en este siglo sino que es una descripción de un locus amoenus, vinculado a las Islas de los Bienaventurados ${ }^{40}$. Es posible que Muret no tuviera en mente la descripción de Canarias, sino que solo se propusiera recoger en el texto los tópicos habituales del mito, pero sin duda, para el lector de esta época no puede disociarse el nombre de Fortunatarum Insulae de la tradición literaria que en Plinio, Mela o Solino se refiere a las Islas Canarias.

\section{El texto de Luis Tribaldos de Toledo}

Luis Tribaldos de Toledo fue un humanista español, geógrafo e historiador, que vivió entre el siglo XVI y el primer tercio del XVII (1558-1634). En una de sus obras, la Epaenesis Iberica, siue laudibus Hispaniae Poematum (1632), incluye un elogio a Canarias con el nombre de Beatorum Insulae

\section{ISLAS DE LOS BIENAVENTURADOS}

Aunque estamos lejos del angosto estrecho del Alcida, aunque se nos llama

La residencia Elísea de las almas de los muertos,

Porque nosotros tenemos por doquier campos tan dichosos

Que hacen felices a los vivos y a los que han cumplido su destino, Islas Afortunadas se nos llama: pues estamos Bajo el afortunado Imperio de los Íberos.

A diferencia del texto de Muret, no podemos pensar que el elogio no se refiere al archipiélago, porque el propio autor anota el nombre de "Islas de Canaria" como glosa marginal del poema. Por ello,

40 Trinidad Arcos Pereira - María Elena Curbelo Tavío (2001), “La Fortunatarum Insularum descriptio de Marc-Antoine Muret en el ms. 1854 de la Biblioteca Nacional de Madrid", Boletín Millares Carlo 20, 73-83. 
afirma que son islas Afortunadas porque están bajo el Imperio de los Íberos ${ }^{41}$. Es un elogio en el que, excepto la mención de pertenecer a la corona española, los rasgos por los que se celebra a Canarias están tomados del mito de las Islas de los Bienaventurados. Este hecho sorprende porque Tribaldos es un geógrafo, traductor de la Chorographia de Mela al español y buen conocedor de los textos de Plinio, pero cuando se plantea su elogio a las Canarias, recurre al mito y no a la información que recogen los textos antiguos o a la realidad de las Islas en el siglo XVII.

\section{A modo de conclusión}

Como conclusión, creo que podemos afirmar que la vinculación de Canarias con las culturas del Mediterráneo y especialmente con la civilización romana es clara y evidente, por los testimonios de los textos y por los hallazgos arqueológicos que conocemos. Al mismo tiempo, es innegable que la visión mítica está indisolublemente ligada a las Islas Canarias en el imaginario occidental y sigue siendo hoy día una poderosa imagen del archipiélago ampliamente utilizada en su promoción como destino turístico. Por ello, para abordar los textos, en primer lugar, es necesario deslindar los datos reales de la descripción mítica y, luego, estudiarlos desde una investigación multidisciplinar, en la que los hallazgos arqueológicos, los conocimientos de la geografía y del paisaje antiguos, los conocimientos náuticos y la interpretación filológica se apoyen mutuamente para entender mejor los textos y aportar un mejor conocimiento de esta etapa de la historia de Canarias y, por extensión, de las culturas mediterráneas, especialmente de la romana, y de su presencia en esta región del Atlántico que fue el confín occidental del mundo en la Antigüedad.

41 Trinidad Arcos Pereira - Gregorio Rodríguez Herrera (2002), “Las Islas del Atlántico en la Epaenesis Iberica de Luis Tribaldos de Toledo", Humanistica Lovaniensia 51, 273284. 


\section{BIBLIOGRAFÍA}

Álvarez Delgado, Juan (1945), “Las “islas Afortunadas' en Plinio", Revista de Historia 9, 2661.

del Arco, María del Carmen - del Arco, María Mercedes - Benito, Carmen y Rosario, María Candelaria (2016), Un taller de púrpura en los límites de la Ecúmene. Lobos 1 [Fuerteventura Islas Canarias]. Primeros resultados, Tenerife, Museo Arqueológico de Tenerife.

Arcos Pereira, Trinidad - Curbelo Tavío, María Elena (2001), "La Fortunatarum Insularum descriptio de Marc-Antoine Muret en el ms. 1854 de la Biblioteca Nacional de Madrid", Boletín Millares Carlo 20, 73-83.

Arcos Pereira, Trinidad - Rodríguez Herrera, Gregorio (2002), “Las Islas del Atlántico en la Epaenesis Iberica de Luis Tribaldos de Toledo", Humanistica Lovaniensia 51, 273-284.

Arcos Pereira, Trinidad - Rodríguez Herrera, Gregorio (2002), “Las Islas del Atlántico en la Epaenesis Iberica de Luis Tribaldos de Toledo", Humanistica Lovaniensia 51, 273-284.

Arcos Pereira, Trinidad-Santana Santana, Antonio (2004), “ Plinio, nat. VI, 203: ¿Ortus u Occasus petatur?, Latomus 63/1, 137-150.

Atoche Peña, Pablo (1993), “Excavaciones arqueológicas en 'El Bebedero' (Teguise, 
Lanzarote). Segunda Campaña 1987", Eres: Arqueología / Bioantropología 4, 7-19.

Atoche Peña, Pablo (1995-1996), "Resultados preliminares de la tercera campaña de excavaciones arqueológicas en 'El Bebedero' (Teguise, Lanzarote) 1990", Vegueta: Anuario de la Facultad de Geografía e Historia 2, 30-44.

Atoche Peña, Pablo (2011), “Excavaciones arqueológicasen el sitio de Buenavista (Lanzarote): nuevos datos para el estudio de la colonización protohistórica del archipiélago canario", Gerión 29, 59-82.

Atoche Peña, Pablo - Ramírez Rodríguez, $M^{a}$ Ángeles (2011), "Nuevas dataciones radiocarbónicas para la protohistoria canaria: El yacimiento de Buenavista (Lanzarote), Anuario de Estudios Atlánticos 57, 139-170.

Atoche Peña, Pablo - Ramírez Rodríguez, $M^{a}$ Ángeles (2017), "C ${ }^{14}$ references and cultural sequence in the Proto-history of Lanzarote (Canary Islands)", Iber-Crono. Actas del Congreso de Cronometrías Para la Historia de la Península Ibérica, Barcelona, 272-285.

Atoche Peña, Pablo - Ramírez Rodríguez, $M^{a}$ Ángeles (2017), “Gentes del ámbito cultural romano en la protohistoria de Canarias", en Germán Santana Henríquez - Luis Miguel Pino

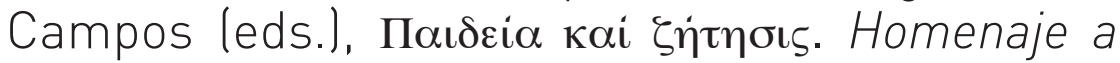
Marcos Martínez, Madrid, 131-140.

Atoche Peña, Pablo - Ramírez Rodríguez, Ma 
Ángeles (2018), “El yacimiento de Buenavista, un asentamiento fenicio-púnico en Lanzarote (Islas Canarias) (circa 930-360 a.n.e.)", Actes du VIIeme Congrès international des études phéniciennes et puniques, Túnez, 365-380.

Atoche Peña, Pablo et al. (1989), El yacimiento arqueológico de "El Bebedero" (Teguise, Lanzarote). Resultados de la primera campaña de excavaciones, La Laguna.

Atoche Peña, Pablo et al. (1995), Evidencias arqueológicas del mundo romano en Lanzarote (Islas Canarias), Arrecife.

Atoche Peña, Pablo et al. (1999), “Pozos con cámara de factura antigua en Rubicón (Lanzarote)", VII Jornadas de Estudios sobre Lanzarote y Fuerteventura, Arrecife, 365-419.

Atoche Peña, Pablo et al. (2006), “Excavaciones arqueológicas en el yacimiento de Buenavista (Tiagua, Lanzarote): primera campaña", Canarias Arqueológica: Arqueología / bioantropología, 17, 9-52.

Atoche Peña, Pablo et al. (2010), “Segunda campaña de excavaciones arqueológicas en el yacimiento de Buenavista (Teguise, Lanzarote): resultados preliminares", Canarias Arqueológica: Arqueología / bioantropología, 18, 1-55.

Conde Salazar, Matilde (1992), "Introducción" a Antonio de Nebrija, Cerco al reino de Granada, Madrid, UNED. 
Delgado Delgado, José A. (2001), “Las Islas de Juno: ¿hitos de la navegación en el Atlántico en época arcaica", The Ancient History Bulletin 15.1-2, 29-43.

Díaz Tejera, Alberto (1988), “Las Canarias en la Antigüedad", en F. Morales Padrón (ed.), Canarias y América, Sevilla, 13-32.

García García, Alicia María (2007), Juba II, rey de Mauritania: traducción y comentario de sus fragmentos, Tesis doctoral presentada en la Universidad de La Laguna, (https://dialnet. unirioja.es/servlet/tesis? codigo $=39611 \&$ orden $=4$ 29248\&info=link, consulta 24/04/2020).

García García, Alicia María (2007), “Una aproximación al texto 202-205 del libro VI de Plinio el Viejo sobre las Fortunatae Insulae", Fortunatae $18,19-41$.

García García, Alicia María (2009) “El informe de Juba II sobre las Fortunatae Insulae (Plinio el Viejo, HN, VI, 202-205)", Revista Tabona 17, 141164.

García-Talavera Casañas, Francisco (2003), “Depósitos marinos fosilíferos del Holoceno de La Graciosa (Islas Canarias) que incluyen restos arqueológicos", Revista de la Academia Canaria de Ciencias 14 (n. 3-4), 19-35.

González Antón, Rafael - del Arco Aguilar, María del Carmen (2009), “Navegaciones exploratorias en Canarias a finales del II Milenio a.C. e inicios del primero. El cordón litoral de La Graciosa 
(Lanzarote)", Canarias Arqueológica 17 (anejo 1), 9-80.

Gozalbes Cravioto, Enrique (1993), “Algunas observaciones acerca del Periplo de Hannon", Hispania Antiqua 17, 7-19.

Gozalbes Cravioto, Enrique (2000), “Más allá de Cerné", Eres 9, 9-42.

Instituto Geológico y Minero de España (2006), Mapa Geológico de Fuerteventura a escala 1:100.000, Madrid, 1 hoja y memoria.

Instituto Geológico y Minero de España (19281972), Mapa Geológico de España a escala 1:50.000, “Hoja 1122-Jandía”, Madrid.

de Jáuregui, Juan José (1954), “Las Islas Canarias y la carrera del oro y la púrpura en el periplo de Hannón", en I Congreso Arqueológico del Marruecos Español (Tetuán, 1953), Tetuán, 271-276.

Lipinski, Edward (2004), Itineraria Phoenicia, Lovaina-Paris-Dudley, MA.

Nebrija, Antonio de (1992), Cerco al reino de Granada, edición y traducción de Matilde conde Salazar, Madrid, UNED.

Martínez, Marcos (1992), “Canarias en la Mitología: historia mítica del archipiélago", Santa Cruz de Tenerife.

Martínez, Marcos (1996), Las Islas Canarias de la Antigüedad al Renacimiento: nuevos aspectos, 
Santa Cruz de Tenerife.

Martínez, Marcos (1999), "Las Islas de los Bienaventurados: historia de un mito en la literatura griega arcaica y clásica", Cuadernos de Filología Clásica: estudios griegos e indoeuropeos 9, 243-279.

Martínez, Marcos (2010), "Islas míticas en relación con Canarias", Cuadernos de Filología Clásica: estudios griegos e indoeuropeos 20, 39-158.

Martínez, Marcos (2014), “Las Islas de los Bienaventurados / Afortunadas en las literaturas griega y latina de las épocas helenística e imperial (I)", en Ángel Martínez Fernández (coord.), Agalma: ofrenda desde la Filología Clásica a Manuel García Tejeiro, Valladolid, 941-948.

Martínez, Marcos (2014), “Las Islas de los Bienaventurados / Afortunadas en las literaturas griega y latina de las épocas helenística e imperial (II)", en Luis Miguel Pino Campos - Germán Santana Henríquez (eds.), Kalos kai agazos aner. Didascalou paradeigma: homenaje al profesor Juan Antonio López Férez, Madrid, 549-448.

Mederos Martín, Alfredo - Escribano Cobo, Gabriel (1997), “Una etapa en la ruta MogadorCanarias: cerámica romana en Lanzarote y su relación con hallazgos submarinos", SPAL. Revista de Prehistoria y Arqueología 6, 221-242.

Mederos Martín, Alfredo - Escribano Cobo, Gabriel (2002), "Las Islas Afortunadas de Juba II. Púnicos-gaditanos y romano-mauretanos en 
Canarias", Gerión 20/1, 315-358.

Alfredo Mederos Martín - Gabriel Escribano Cobo (2006), "Producción y comercio de la púrpura en el litoral Atlántico norteafricano", Rivista di Studi Fenici 34, 1, 71-95.

Montesdeoca Medina, José Manuel (2007), "Las Islas Canarias en los islarios (I)", Fortunatae 18, 107-124.

Montesdeoca Medina, José Manuel (2008), “Las Islas Canarias en los islarios (II)", Fortunatae 18, 101-126.

Santana Santana, Antonio - Arcos Pereira, Trinidad - Atoche Peña, Pablo - Martín Culebras, José (2002), El conocimiento geográfico de la costa noroccidental de África en Plinio: la posición de las Canarias, Hildesheim - New York.

Santana Santana, Antonio - Arcos Pereira, Trinidad (2006), "Las dos islas Hespérides atlánticas (Lanzarote y Fuerteventura, Islas Canarias, Españal durante la Antigüedad: del mito a la realidad", Gerión 24, 85-100.

Santana Santana, Antonio - Arcos Pereira, Trinidad (2003-2007), “La expedición de Juba II a las Islas Afortunadas y el meridiano cero del Orbis Terrarum", Orbis Terrarum. Internationale Zeit-zchrift für Historische Geographie der Alten Welt 9, 143-158.

Santana Santana, Antonio - Arcos Pereira, Trinidad (2010), “El Periplo de Hanón: una propuesta de 
interpretación", Latomus 69/1, 3-17.

Schmitt, P. (1968), "Connaissance des îles Canaries dans l'Antiquité", Latomus 27, 362-391.

Tejera Gaspar, Antonio (2001), “Qué es la Insula Capraria de Plinio?", Faventia 23/2, 43-49. 